\title{
Impact Mechanisms of Shallow Cumulus Convection on Tropical Climate Dynamics*
}

\author{
Roel A. J. Neggers, ${ }^{+}$J. David Neelin, And Bjorn Stevens \\ Department of Atmospheric and Oceanic Sciences, University of California, Los Angeles, Los Angeles, California
}

(Manuscript received 12 January 2006, in final form 1 September 2006)

\begin{abstract}
Subtropical shallow cumulus convection is shown to play an important role in tropical climate dynamics, in which convective mixing between the atmospheric boundary layer and the free troposphere initiates a chain of large-scale feedbacks. It is found that the presence of shallow convection in the subtropics helps set the width and intensity of oceanic ITCZs, a mechanism here termed the shallow cumulus humidity throttle because of the control exerted on the moisture supply to the deep convection zones. These conclusions are reached after investigations based on a tropical climate model of intermediate complexity, with sufficient vertical degrees of freedom to capture (i) the effects of shallow convection on the boundary layer moisture budget and (ii) the dependency of deep convection on the free-tropospheric humidity. An explicit shallow cumulus mixing time scale in this simple parameterization is varied to assess sensitivity, with moist static energy budget analysis aiding to identify how the local effect of shallow convection is balanced globally. A reduction in the mixing efficiency of shallow convection leads to a more humid atmospheric mixed layer, and less surface evaporation, with a drier free troposphere outside of the convecting zones. Advection of drier free-tropospheric air from the subtropics by transients such as dry intrusions, as well as by mean inflow, causes a substantial narrowing of the convection zones by inhibition of deep convection at their margins. In the tropical mean, the reduction of convection by this narrowing more than compensates for the reduction in surface evaporation. Balance is established via a substantial decrease in tropospheric temperatures throughout the Tropics, associated with the reduction in convective heating. The temperature response-and associated radiative contribution to the net flux into the column - have broad spatial scales, while the reduction of surface evaporation is concentrated outside of the convecting zones. This results in differential net flux across the convecting zone, in a sense that acts to destabilize those areas that do convect. This results in stronger large-scale convergence and more intense convection within a narrower area. Finally, mixed layer ocean experiments show that in a coupled ocean-atmosphere system this indirect feedback mechanism can lead to SST differences up to $+2 \mathrm{~K}$ between cases with different shallow cumulus mixing time, tending to counteract the direct radiative impact of low subtropical clouds on SST.
\end{abstract}

\section{Introduction}

Shallow cumulus is widespread in the subtropics, and can have considerable importance from the perspective of climate system dynamics. While past field studies have revealed much about shallow convection itself, numerical experiments by Tiedtke et al. (1988) were the first to quantify the impact of shallow cumulus con-

\footnotetext{
* Institute of Geophysics and Planetary Physics Contribution Number 6245.

+ Current affiliation: European Centre for Medium-Range Weather Forecasts, Reading, United Kingdom.
}

Corresponding author address: R. A. J. Neggers, ECMWF, Shinfield Park, Reading, Berkshire RG2 9AX, United Kingdom. E-mail: Roel.Neggers@ecmwf.int vection on large-scale tropical circulations. They found that the introduction of a modified representation of shallow convection in the forecast system of the European Centre for Medium-Range Weather Forecasts (ECMWF) significantly impacted the larger-scale dynamics and the model climate. They argued that more effective mixing by trade wind clouds helped ventilate the subcloud mixed layer, thereby increasing surface evaporation, which in turn lead to greater humidity convergence within the ITCZ and more active deep convection. Subsequent studies using general circulation models (GCMs) have corroborated these arguments (Slingo et al. 1994; Gregory 1997; Jakob and Siebesma 2003).

These results help motivate our study of the interaction mechanisms between subtropical shallow cumulus and larger-scale circulations within the near Tropics.

DOI: 10.1175/JCLI4079.1

(C) 2007 American Meteorological Society 
Horizontal humidity advection is likely to be important in this interaction, as it carries air of a certain humidity state from the subtropics toward the ITCZ. Horizontal moisture advection has been found in models to affect deep convection on the margins of the convective zones in mechanisms that involve feedbacks with the largescale circulation (Neelin et al. 2003; Chou and Neelin 2004; Chou et al. 2006). Horizontal moisture advection in observations is often manifest in pronounced transients, whether they be in the form of moist filaments (Newell et al. 1992; Newell and Zhu 1994; Pierrehumbert and Yang 1993) exporting moisture out of the Tropics, or dry intrusions importing dry air (e.g., Parsons et al. 2000) into the Tropics. While the atmospheric boundary layer (ABL) moisture is restored toward saturation by the surface fluxes on a time scale of a day or so, the free-tropospheric moisture is largely decoupled from the ABL except where convection occurs. As a result, the impact of dry intrusions on the deep Tropics may in part be regulated by the mixing efficiency of shallow convection. Dry intrusions are observed to significantly reduce the occurrence of deep convection and precipitation. Sensitivity of deep convection to local tropospheric humidity has also been demonstrated in cloud-resolving models Derbyshire et al. (2004).

Here we postulate that shallow convection, by controlling the humidity in the lower troposphere that is advected into the ITCZ margins, participates in interactions with the large-scale circulation that impact the ITCZs. We term this the "shallow convective humidity throttle" (Cu-q throttle), since shallow convection controls the fuel available to the deep convective zones.

To investigate the role of shallow cumulus on largescale tropical circulations, we use an intermediate complexity climate model, the quasi-equilibrium tropical circulation model (QTCM; Neelin and Zeng (2000, hereafter NZ00; Zeng et al. 2000). It has been shown to reproduce tropical climatology to a reasonable degree (Zeng et al. 2000). In this study, an extra degree of freedom for humidity is introduced in the model so as to allow varying degrees of coupling between the atmospheric mixed layer and free-tropospheric humidity field. Because the previous version of the QTCM has only one vertical basis function for moisture, both the atmospheric mixed layer and the free troposphere couple to the surface humidity on the same time scale. As a result it underestimates the variance due to dry intrusions and other humidity transients in the free troposphere. Introducing an additional basis function for moisture greatly increases the humidity transients in the QTCM.

The aim here is to distinguish between a surface layer of high turbulence, which we will refer to as the atmospheric mixed layer, and the free troposphere into which moisture is tranferred primarily by shallow and deep cumulus convection. It would be tempting to refer to the former as the subcloud mixed layer since it is the layer of moisture source for the cumulus convection, except that this layer often includes boundary layer cloud. The term atmospheric boundary layer is sometimes interpreted to include the shallow cumulus layer.

The introduction of an extra basis function that allows one to differentiate the atmospheric mixed-layer and free-tropospheric temperature implies changes in the QTCM convection scheme. A simple first-order shallow convection scheme is embedded in an already existing Betts-Miller framework for deep convection. As for deep convection, shallow cumulus intensity will be defined by a typical adjustment time scale for this type of convection, which in effect defines the degree of coupling between the ABL and the free troposphere. Apart from shallow and deep convection, this change also results in a mode of convection, which, for reasons we outline below, we interpret as cumulus congestus. The net result is that the addition of an extra vertical degree of freedom in the QTCM moisture field allows at least some effects of the three basic types of convection thought to dominate the cloud-type distribution in the Tropics (Johnson et al. 1999) to be represented.

In analyzing the effects of shallow convection on the large-scale flow we use the moist static energy (MSE) framework (Neelin and Held 1987). Such an approach has been used successfully to relate tropical temperature, humidity, precipitation, and divergence anomalies in tropical climate phenomena such as El Niño and teleconnections (e.g., Su et al. 2003; Su and Neelin 2002, 2003; Chou and Neelin 2004). By calculating MSE budgets it should be possible to interpret just how modifications arising from changes to the representation of shallow convection are manifest on the model climate.

To summarize, using the QTCM framework, the sensitivity of model climate to tropospheric humidity transients and shallow cumulus convection is studied. Section 2 briefly describes the QTCM and the introduction of an extra vertical degree of freedom to the model's representation of moisture. In section 3 the associated changes in the convection scheme are formulated. Section 4 discusses the methodology of the study, consisting of a series of simulations with varying shallow cumulus intensity. In section 5 the associated changes in mean tropical climatology are presented, while in section 6 the QTCM humidity field is examined in more detail. In section 7 the tropical MSE budget is used to help us understand how changes to our representation of shallow cumulus affect the large-scale circulation. 
While most results are presented for fixed SST experiments, section 8 addresses feedbacks that occur when coupled to a mixed layer ocean. In section 9, our findings are summarized, and their implications are discussed.

\section{QTCM}

\section{a. Short description of the standard model}

The full description of the QTCM is given by NZ00 and Zeng et al. (2000). One of the core assumptions at the basis of the QTCM that greatly simplifies the tropical dynamics is the assumption of a fixed vertical temperature structure, which is justified by the fact that the tropical temperature tends to remain close to the moist adiabat. Through the pressure gradient term, this assumed vertical structure determines the basis function for the baroclinic wind component.

Explicit convection in the single basis function (1BF) QTCM is by definition precipitating, requiring only representation of column averaged heating or moistening (vertical redistribution of moisture within the column is implicitly assumed to occur quickly yielding the moisture profile of the basis function). The deep convection is modeled using the adjustment frame work of Betts (1986, hereafter B86) and Betts and Miller (1986, hereafter BM86). It keeps the temperature profile close to the moist adiabat by using a relatively fast convective time scale to adjust the column in response to destabilization by large-scale processes, hence the words "quasi-equilibrium" in the name QTCM. A short summary of the relevant elements for this paper is given here; for a detailed description, see NZ00.

Conservation of energy implies that the columnaverage latent heat release by deep convection $\left\langle Q_{c}\right\rangle$ is equal to the net humidity sink due to precipitation $\left\langle Q_{q}\right\rangle$ :

$$
\left\langle Q_{c}\right\rangle=-\left\langle Q_{q}\right\rangle .
$$

Following NZ00 both $\langle.$.$\rangle and \hat{\wedge}$ refer to a column average. BM86 and B86 expressed this apparent heat source and sink in the form of a relaxation equation:

$$
\left\langle Q_{c}\right\rangle=\frac{\left\langle T^{c}-T\right\rangle}{\tau_{\mathrm{dp}}}, \text { and }\left\langle Q_{q}\right\rangle=\frac{\left\langle q^{c}-q\right\rangle}{\tau_{\mathrm{dp}}},
$$

where $T$ is the specific enthalpy (i.e., temperature times the isobaric specific heat) and $q$ is the available enthalpy of vaporization (i.e., the water vapor specific humidity times the latent heat, it effectively measures moisture). Hence $T+q$ defines the moist enthalpy. The superscript $c$ denotes the convective adjustment profile. Here $\tau_{\mathrm{dp}}$ defines the convective adjustment time scale, and is assumed to be about $2 \mathrm{~h}$. The term $\left\langle T^{c}-T\right\rangle$ is a measure of convective available potential energy (CAPE), representing that part of the real CAPE that is actually converted into latent heat by precipitation loss. In this paper it will be indicated by CAPE1, to stay compatible with the previous QTCM papers.

Concerning the closure of the convective adjustment profiles, as in NZ00 the BM86 and B86 moisture closure is followed by assuming that $q^{c}$ is a specified function of the saturation humidity profile:

$$
q^{c}=\alpha(p) q_{\mathrm{sat}},
$$

where $\alpha$ reflects the relative humidity structure of the adjustment profile. Writing $T^{c}$ and $T$ each in terms of a constant reference profile, $T_{r}^{c}(p)$ and $T_{r}(p)$, and a vertical basis function $a_{1}(p)$ associated with convective quasi-equilibrium, gives

$$
\begin{aligned}
T & =T_{r}(p)+T_{1}(x, y, t) a_{1}(p), \\
T^{c} & =T_{r}^{c}(p)+T_{1}^{c}(x, y, t) a_{1}(p),
\end{aligned}
$$

where subscript 1 indicates the first, atmosphere-deep basis function for temperature (see NZ00 for a detailed description). Applying (4) to (2) and then substituting in energy conservation, Eq. (1) gives $T_{1}^{c}$ as a function of the thermodynamic state $\{T, q\}$ of the column:

$$
\hat{a}_{1} T_{1}^{c}+\hat{q}^{c}\left(T_{1}^{c}\right)=\hat{a}_{1} T_{1}+\hat{q}-\left(\hat{T}_{r}^{c}-\hat{T}_{r}\right),
$$

where we used that $q_{\text {sat }}$ can be written as a function of $T^{c}$ and $p$, by which the lhs of (5) becomes a unique function of $T_{1}^{c}$. Obtaining $\hat{T}_{1}^{c}$ and $\hat{q}^{c}$ using (5) then enables calculation of $\left\langle Q_{c}\right\rangle$ and $\left\langle Q_{q}\right\rangle$, which appear in the prognostic heat and moisture equations as the convective tendencies.

\section{b. A second basis function for humidity}

The main reasons for introducing an atmospheric mixed layer in the QTCM have been outlined in the introduction. The presence of a shallow layer between the free troposphere and the surface strongly affects the surface sensible and latent heat fluxes, as well as the climatology of tropospheric humidity. Another related issue is the typically high variability present in observed vertical humidity profiles (e.g., Liu et al. 1991). A decoupled two-layer system for humidity in the QTCM, representing an atmospheric mixed layer below a free troposphere, might capture typical advective characteristics of the tropospheric humidity field (e.g., Pierrehumbert and Yang 1993). While the atmospheric mixed layer will be strongly tied to the SST through the surface evaporation, the relatively deep free-tropospheric layer will be dominated by horizontal advection away from regions of deep convection. 
The atmospheric humidity field is far less constrained than the temperature field, which is closely coupled to buoyancy and hence both convection and wave dynamics. Tropospheric temperature is also strongly tied to the large-scale dynamics through the pressure gradient term, a concept that is explicitly used in the QTCM formulation. In contrast, the tropospheric humidity field behaves much more like a passive scalar in the absence of deep convection. To the extent that moisture can be decoupled from the density field its vertical discretization can be done independent of that for temperature and velocity. Thus, the introduction of a second degree of freedom in moisture while retaining the same structure for the rest of the model helps isolate moisture impacts.

\section{c. 2BF formulation}

For moisture $q$ we extend the QTCM 1BF standard model to a two basis function (2BF) version. As described by NZ00 for the $1 \mathrm{BF}$ case, a Galerkin approximation is made around a reference climatological moisture profile $q_{r}(p)$ :

$$
q(x, y, p, t)=q_{r}(p)+\sum_{k=1}^{2} b_{k}(p) q_{k}(x, y, t),
$$

where $k$ is the mode index, $b_{k}$ is the vertical structure function of each mode, and $q_{k}$ is a time-dependent scalar field. There are thus two prognostic equations for moisture.

The choice of the vertical structure functions $b_{k}$ depends on the problem of interest. As our purpose is to introduce an atmospheric mixed layer for humidity, we choose each of the two functions to cover separate layers (see Fig. 1). The first function $b_{1}(p)$ covers the free troposphere (of depth $P_{1}=750 \mathrm{hPa}$ ) without the atmospheric mixed layer (of constant depth $P_{2}=100$ $\mathrm{hPa}$ ), which is covered by the second function $b_{2}(p)$. Within its pressure-depth $P_{k}$ each function $b_{k}$ is nonzero while outside of it, it is zero. An infinitesimal small overlap $\varepsilon$ at mixed-layer top (at $900 \mathrm{hPa}$ ) is introduced to facilitate derivations (see the appendix), letting $\varepsilon \rightarrow$ 0 . Hereafter, a vertical average over layer $k$ is indicated as $\hat{\cdot}_{k} \equiv\langle. .\rangle_{k}$.

An essential concept of the QTCM is that vertical integration is performed before time integration, while still maintaining as much vertical nonlinearity as possible through precalculated constants. We thus work with a mixed layer of constant depth. While a simplification of reality, observations show that the subcloud mixed-layer height in the subtropics is indeed remarkably constant (e.g., Riehl et al. 1951).

Note that the vertical structure functions $b_{k}$ represent

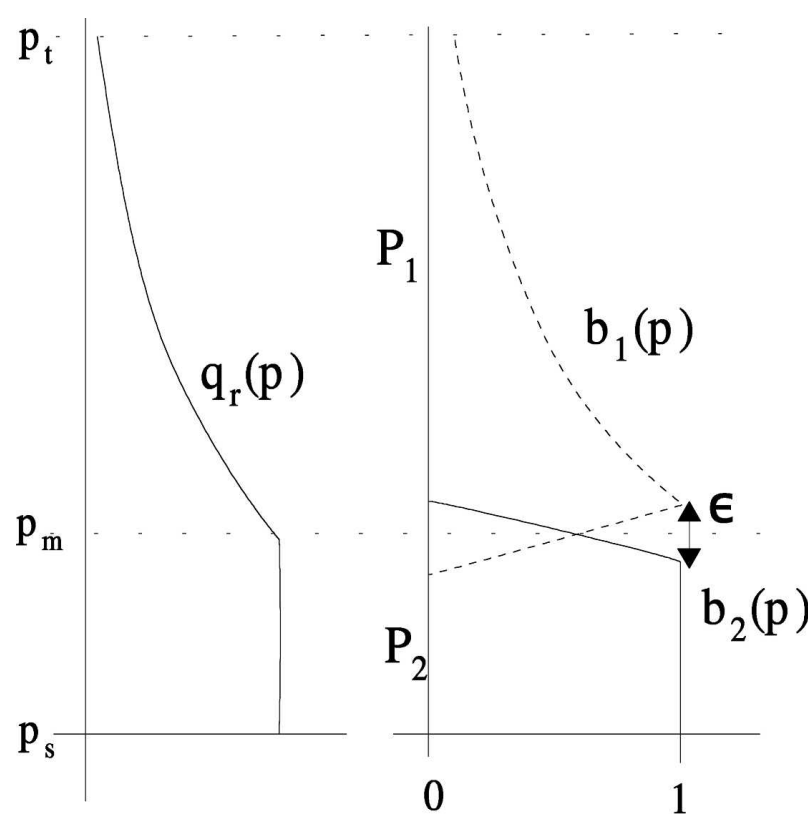

FIG. 1. The configuration of the vertical structure functions $b_{k}$. Perturbations of humidity are strongest in the atmospheric mixed layer and in the lower troposphere.

the vertical distribution throughout each layer of the departures of the actual moisture profile $q$ from a reference profile $q_{r}$. Figure 1 shows that while in the mixed layer (layer 2) the structure function is constant, in the free troposphere (layer 1) the largest absolute changes in humidity take place in the lower troposphere. This enables large moisture differences to exist between layers 1 and 2 at the cloud base, while simultaneously the upper-tropospheric moisture is still close to its characteristic low value.

The technical details of the implementation of the second basis function in the QTCM are relatively straightforward, and follow the notation of NZ00. A short description can be found in the appendix.

\section{The $2 \mathrm{BF}$ convection scheme}

The differentiation of the moisture field between the atmospheric mixed layer and the free troposphere requires modifications to the QTCM convection scheme so as to allow for the redistribution of humidity between the mixed layer and the free troposphere, as well as precipitation. Instead of one type of convection, now three modes can be distinguished based on the relative magnitudes of the convective heating and the convective drying. These are identified as deep convection, cumulus congestus, and shallow convection, as schematized in Fig. 2.

These three types of convection are observed to dominate the cloud-type distribution in the Tropics 

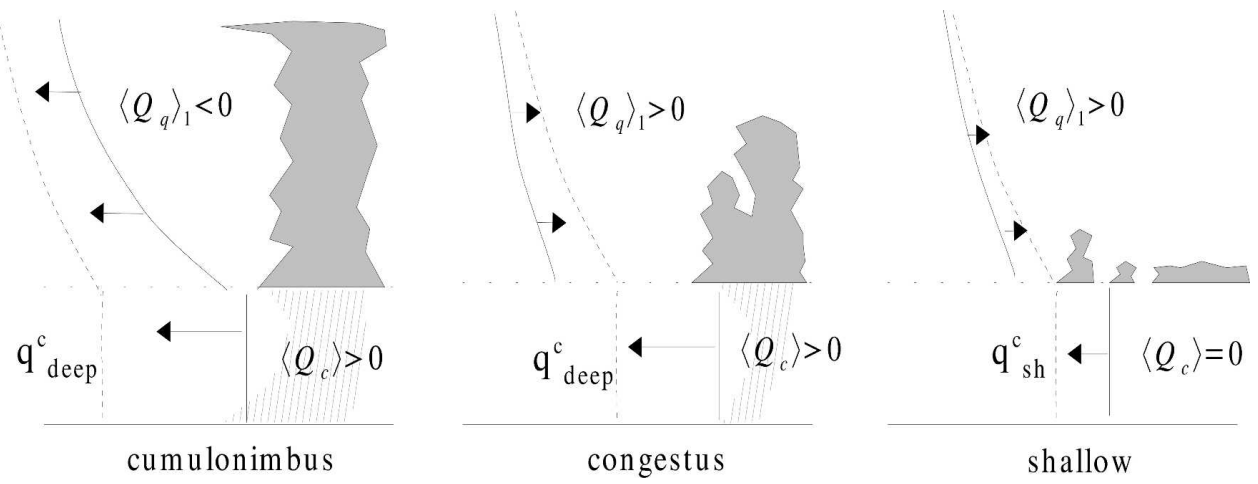

FIG. 2. An overview of three possible scenarios for the two apparent moisture sink terms $\left\langle Q_{q}\right\rangle_{k}$ in the 2BF setup. The dashed line indicates the convective adjustment profile for moisture, $q_{\text {deep }}^{c}$ for deep convection and $q_{\mathrm{sh}}^{c}$ for shallow cumulus convection. The solid line represents the actual humidity profile. The name "congestus" is used as a shorthand term for precipitating shallow convection.

(Johnson et al. 1999). The new convective modes are introduced as an extension of the Betts-Miller framework for deep convection used in the 1BF QTCM. As for deep convection, shallow cumulus intensity will be defined by a typical adjustment time scale.

\section{a. Deep convection}

In the 2BF setup, deep convective CAPE1 is calculated in the same way as in the $1 \mathrm{BF}$ setup, in the sense that the total water vapor path through the whole column is still fed into energy constraint (5) to get $\hat{T}_{1}^{c}$ and $\hat{q}_{c}$. The difference is that $\hat{q}$ now stands for the effective vertically averaged humidity over two layers instead of a single tropospheric layer:

$$
\hat{q}=\sum_{k=1}^{2} \frac{P_{k}}{P_{T}} \hat{q}_{k},
$$

where $P_{T}=P_{1}+P_{2}=850 \mathrm{hPa}$ is the pressure depth of the atmospheric column. The presence of a second degree of freedom for humidity in the model thus affects the deep convective precipitation rate $\left\langle Q_{c}\right\rangle$. The apparent humidity sink now consists of two terms representing the two separate layers:

$$
\left\langle Q_{c}\right\rangle=-\left\langle Q_{q}\right\rangle \equiv-\sum_{k=1}^{2} \frac{P_{k}}{P_{T}}\left\langle Q_{q}\right\rangle_{k} .
$$

As the shallow mixed layer is always relatively moist, determined in large part by the SST, convection typically acts to dry out the atmospheric mixed layer $\left(\left\langle Q_{q}\right\rangle_{2}<0\right)$. Under situations favorable to intense deep convection, the lower troposphere has moisture convergence balanced by the convective moisture sink, so $\left\langle Q_{q}\right\rangle_{1}<0$ as well. However, situations with low-tropospheric humidity can now reduce $\left\langle Q_{c}\right\rangle$ through $\left.\left\langle Q_{q}\right\rangle_{1}\right\rangle$ 0 , a situation corresponding to free-tropospheric moist- ening. This suppresses surface precipitation. The sensitivity of deep convective precipitation to tropospheric humidity thus introduced is visualized in Fig. 3, which shows $\left\langle Q_{c}\right\rangle$ as a function of $T_{1}$ and $q_{1}$. The rapid pickup of precipitation above a critical value of $\hat{q}_{1}$ is the parameterized counterpart seen in observations (Bretherton et al. 2004; Peters and Neelin 2006). For a sufficiently dry lower troposphere $\left\langle Q_{c}\right\rangle$ can even become zero, in which case surface precipitation completely switches off and nonprecipitating cumulus (section 3c) takes over.

\section{b. Congestus}

A separate regime in precipitating convection can now be distinguished in the model. The situation can exist in which net surface precipitation occurs but in which convection still moistens the free troposphere:

$$
\begin{aligned}
\left\langle Q_{c}\right\rangle & >0, \\
\left\langle Q_{q}\right\rangle_{1} & >0,
\end{aligned}
$$

see Figs. 2 and 3 (the area between the two zero isolines). We use cumulus congestus to describe this regime, although it can also be thought of as a blend of deep and nonprecipitating shallow convection. Note that (5) implies $T^{c}$ is adjusted to a smaller value when the tropospheric air is dry than when it is wet, as illustrated by Fig. 3. Thus the impact of free-tropospheric humidity affects the buoyancy term $\left(T^{c}-T\right)$, and thus the precipitation.

\section{c. Shallow cumulus}

When CAPE1 $\leq 0$ no precipitating convection is expected in this model. Nevertheless, redistribution of humidity can still take place between the two layers, without creating net surface precipitation: 


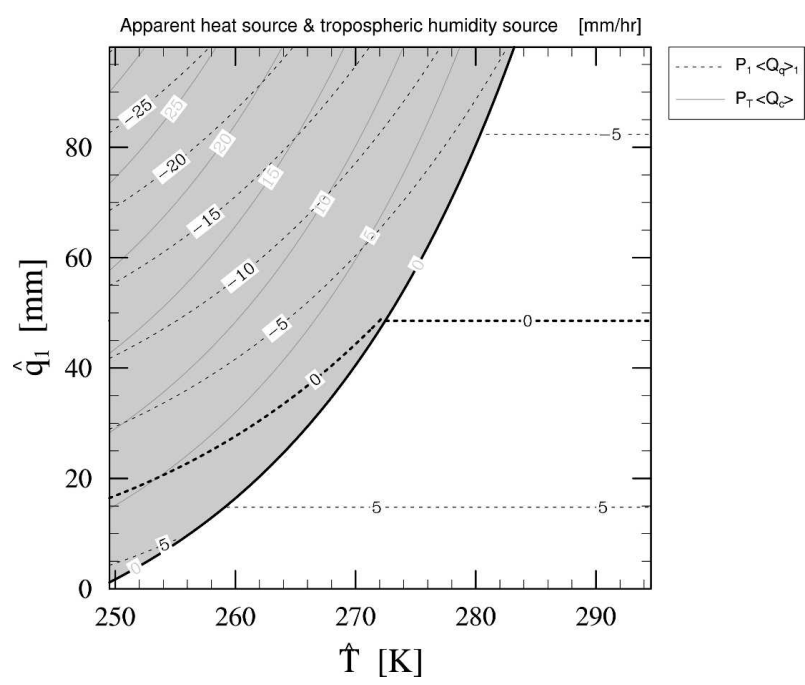

FIG. 3. Visualization of convective closure in the 2BF system. Convective heating $\left\langle Q_{c}\right\rangle$ (solid gray contours and shaded where positive) is determined by (2), (5), and (3) where these yield positive values (zero otherwise). The free-tropospheric humidity source $\left\langle Q_{c}\right\rangle_{1}$ (dotted black contours) is similarly determined where $\left\langle Q_{c}\right\rangle>0$ and otherwise follows the shallow cumulus closure (12), (13), and (16). Contoured at $5 \mathrm{~mm} \mathrm{~h}^{-1}$. These are displayed as a function of tropospheric average temperature (given by $\hat{T} \equiv$ $\hat{T}_{r}+\hat{a}_{1} T_{1}$ ) and height-averaged tropospheric humidity $\hat{q}_{1}$ (given as integrated liquid water equivalent in $\mathrm{mm}$ ). In this example, mixed-layer humidity $\hat{q}_{2}$ is fixed at a typical tropical value of $20 \mathrm{~g}$ $\mathrm{kg}^{-1}(=20 \mathrm{~mm})$. Not all regions of the diagram occur in simulations.

$$
\begin{aligned}
\left\langle Q_{c}\right\rangle & =0, \\
P_{2}\left\langle Q_{q}\right\rangle_{2} & =-P_{1}\left\langle Q_{q}\right\rangle_{1} .
\end{aligned}
$$

This situation represents nonprecipitating convection, which we identify with shallow cumulus convection. The extra condition (11) was also used by BM86 and B86 in their shallow convection scheme.

In the Betts-Miller framework, shallow convection is expressed as a relaxation term acting on the excess of mixed-layer humidity over its adjustment value $q_{\mathrm{sh}}^{c}$,

$$
\left\langle Q_{q}\right\rangle_{2}=\frac{\left\langle q_{\mathrm{sh}}^{c}-q\right\rangle_{2}}{\tau_{\mathrm{sh}}},
$$

where $\tau_{\mathrm{sh}}$ represents the typical time in which shallow cumulus vertical transport tends to reduce humidity differences between the atmospheric mixed layer and free troposphere. Condition (12) implies the adjustment value for shallow convection:

$$
\hat{q}_{\mathrm{sh}}^{c}=\hat{q} .
$$

This represents the state toward which the system is driven by the redistribution of moisture within a col- umn. Writing the vertical structure of $q_{\mathrm{sh}}^{c}$ in terms of the same BF used for $q$, gives

$$
q_{\mathrm{sh}}^{c}(x, y, p, t)=q_{r}(p)+\sum_{k=1}^{2} b_{k}(p) q_{\mathrm{sh}, k}^{c}(x, y, t) .
$$

We further assume that the shallow cumulus mixing drives the moisture in the free troposphere to a profile such that the values at cloud base are equal to those in the mixed layer, so $q_{\mathrm{sh}, 1}^{c}=q_{\mathrm{sh}, 2}^{c}$. With (14), this yields the shallow adjustment projection coefficients $q_{\mathrm{sh}, k}^{c}$,

$$
q_{\mathrm{sh}, 2}^{c}=q_{\mathrm{sh}, 1}^{c}=\frac{P_{1} \hat{b}_{1} q_{1}+P_{2} \hat{b}_{2} q_{2}}{P_{1} \hat{b}_{1}+P_{2} \hat{b}_{2}}
$$

which is a diagnostic function of $q_{1}$ and $q_{2}$. Comparing it to the deep convective moisture closure (3), this implies that for nonprecipitating cumulus, the degree of subsaturation is set by mixing processes, rather than specified.

To derive a typical first-order value for $\tau_{\mathrm{sh}}$, one can convert (13) into flux units by multiplying with height and then making the mass flux assumption (e.g., Ooyama 1971; Yanai et al. 1973; Betts 1975) for the left-hand side. This gives

$$
z_{b}\left\langle Q_{q}\right\rangle_{2} \approx-m\left(q_{t}^{\text {core }}-q_{t}^{\text {env }}\right)_{b} .
$$

Here $z_{b}$ is the mixed-layer depth and $m$ is the shallow cumulus mass flux at $z_{b}$. The mass flux acts to reduce the total specific humidity difference between the cloud environment $q_{t}^{\text {env }}$ and the active cloudy thermals $q_{t}^{\text {core }}$ by convective overturning. In the rising undiluted parcel interpretation, these rising thermals still have specific humidity levels very close to mixed-layer values. Accordingly, it makes sense to scale the cloud excess with the excess over the shallow adjustment profile:

$$
\left(q_{t}^{\text {core }}-\bar{q}_{t}\right)_{b} \sim\left(q-q_{\mathrm{sh}}^{c}\right)_{2} .
$$

Using $z_{b}=1000 \mathrm{~m}$ and $m=0.01 \mathrm{~m} \mathrm{~s}^{-1}$ as typical values for trade wind cumulus (e.g., Siebesma and Cuijpers 1995) and combining (13)-(18), this gives

$$
\tau_{\mathrm{sh}}=\frac{z_{b}}{m} \sim 1 \times 10^{5} \mathrm{~s}
$$

This mass flux-based shallow convective adjustment time scale serves as a reference value in the sensitivity test discussed in the next sections. Of course, $\tau_{\mathrm{sh}}$ could be related to the state of the model, as is implicitly done in a mass flux framework. This would result in a spatially varying shallow adjustment time scale, an idea we explore further in subsequent work. 


\section{d. Shallow cumulus humidity throttle}

At this point some impact mechanisms of shallow cumulus convection on the tropical climate system in the QTCM can a priori be distinguished. Locally, at the edges of the ITCZ, during a dry tropospheric intrusion shallow cumulus will temporarily replace precipitating convection. Only after shallow convection has moistened the troposphere sufficiently can deep convection again occur (e.g., Parsons et al. 2000). Remotely, in the subtropical trade wind regions, shallow cumulus continuously maintains the humidity levels of the lower free troposphere by vertical humidity transport at the cloud base. This humidity is then advected horizontally into the ITCZ, where it helps maintain deep convective occurrence and intensity. Advection of less-moistened air, on the other hand, tends to reduce convection at the margins of the ITCZs (Chou and Neelin 2004).

This set of feedbacks, in which the intensity of shallow convection creates both local and remote impacts by its control of tropospheric moisture $q$, is what we term the shallow cumulus humidity throttle (or $\mathrm{Cu}-q$ throttle) mechanism. Here we test impacts of the $\mathrm{Cu}-q$ throttle by varying shallow cumulus parameters. We then diagnose the chain of feedbacks at larger scales.

\section{Methodology}

A sensitivity test is performed on the QTCM climatology for the gradual decoupling of the atmospheric mixed layer from the free troposphere. This is done through varying the value of a spatially constant $\tau_{\text {sh }}$. Although a constant $\tau_{\mathrm{sh}}$ might not be realistic, it does (i) reveal the first-order impacts of shallow cumulus activity on the climate system, and (ii) facilitate comparison to the original 1BF QTCM.

Over a series of separate runs the shallow convective adjustment time scale $\tau_{\mathrm{sh}}$ is altered, spanning its realistic range between half and twice its typical value as was derived in (19). This range is chosen to span the range one might encounter in convection schemes in GCMs. For the sake of completeness, the range is extended to $1200 \mathrm{~s}$ (the model time step), so as to recover the limit in which the atmospheric mixed-layer and free-troposphere humidity structure are effectively slaved to one another. Sections 5-7 deal with the results of this sensitivity test, using the MSE framework.

Each run covers $17 \mathrm{yr}$, over which averages are also calculated. The observed sea surface temperature (SST) is specified as a boundary condition. The impacts of an interactive oceanic mixed layer in this problem are also explored, and summarized in section 8 .

\section{Results: Mean climatology}

Comparing a series of numerical experiments with different $\tau_{\mathrm{sh}}$ reveals significant changes in the tropical and subtropical climatology. Figure 4a shows that the total column water vapor path drops everywhere as $\tau_{\text {sh }}$ increases. This is most significant in the subtropics, where subsidence associated with the Hadley circulation is effective in drying the free troposphere. As the shallow convective transport is decreased, the mixed layer moistens and the free troposphere dries out. Roughly comparing to SSM/I observations (not shown here) reveals that the general structure of the QTCM water vapor path field becomes more realistic, with narrower ITCZs and drier subtropics as $\tau_{\mathrm{sh}}$ increases from unrealistically small values to values on the order of a day.

The associated drop in surface evaporation is shown in Fig. 4b. The more humid atmospheric mixed layer with increasing $\tau_{\mathrm{sh}}$ is the direct cause for this reduction, which is consistent with the results of Tiedtke et al. (1988). In contrast, in the central axis of the oceanic ITCZs the surface evaporation has increased.

The change in the precipitation rate is plotted in Fig. $4 c$. In general, the edges of the precipitating ITCZ area suffer a significant decrease in precipitation rate, up to $5 \mathrm{~mm} \mathrm{day}^{-1}$ in some areas. In contrast, the core axes of the oceanic ITCZs experience an increase of up to 6 $\mathrm{mm}$ day $^{-1}$. The spatial pattern of the positive precipitation matches that of the positive evaporation change in Fig. 4b, although the local amplitude of precipitation (noting $1 \mathrm{~mm} \mathrm{day}^{-1} \approx 28 \mathrm{~W} \mathrm{~m}^{-2}$ ) is substantially larger. Comparing Figs. $4 \mathrm{c}$ to $4 \mathrm{a}$ shows that the areas of significant decrease in precipitation rate always correspond to lower water vapor paths. Precipitation reductions over the continents are approximately as strong as over the oceans, although precipitation increases tend not to occur over land.

Only the month of July is shown here, although other months behave similarly, with the spatial patterns moving according to the seasonal movements of the convection/subsidence regions. To optimize readability and reduce the number of plots, only July will be discussed. The seasonal dependence of the climate mechanisms involved is addressed in the discussion in section 9 .

\section{Humidity transients}

The 2BF QTCM convection scheme as described in section 3 implies that precipitating deep convection is sensitive to tropospheric humidity. The fact that the precipitation decrease at the edges of the ITCZ with increasing $\tau_{\text {sh }}$ coincides with significantly lower water 
a)

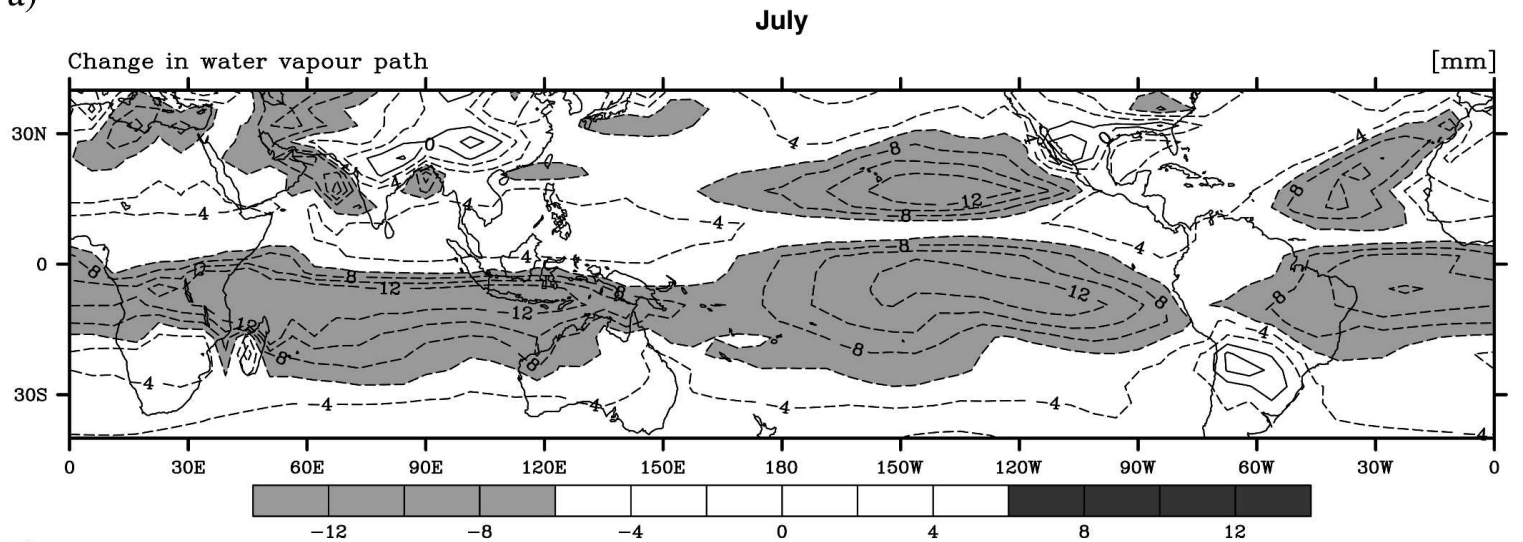

b)

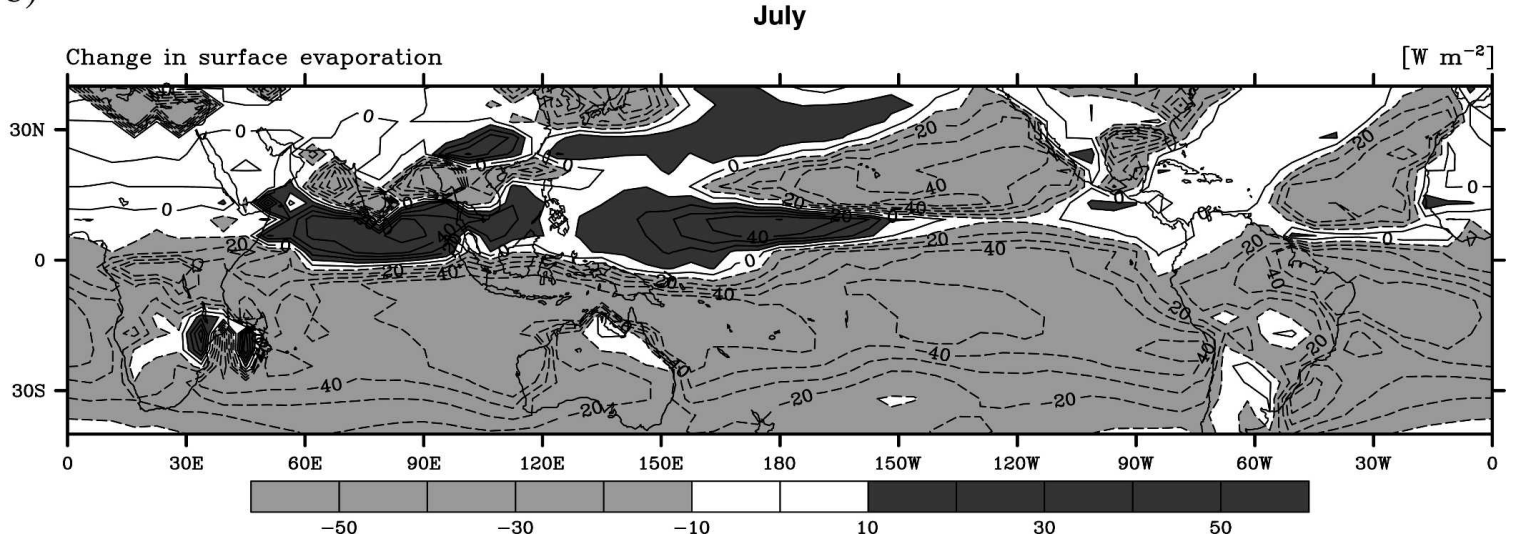

c)

FIG. 4. The change in the July climatology of (a) water vapor path ( $\mathrm{mm})$, (b) surface evaporation $\left(\mathrm{W} \mathrm{m}^{-2}\right)$, and (c) precipitation rate $\left(\mathrm{mm} \mathrm{day}^{-1}\right)$ for the $\tau_{\mathrm{sh}}=200000 \mathrm{~s}$ run minus the $\tau_{\mathrm{sh}}=1200 \mathrm{~s}$ run.

vapor paths suggests that this feedback is indeed occurring in the model.

The QTCM tropospheric humidity field $\hat{q}_{1}$ during the run with $\tau_{\mathrm{sh}}=1 \times 10^{5} \mathrm{~s}$ on a mid-December day is shown in Fig. 5. The humidity field is far from smooth, featuring relatively thin, elongated plumes of moist and dry air. These filaments cover a latitude range on the order of $40^{\circ}$, and the dry air seems able to reach all the way to the equator on some occasions. The horizontal gradients between moist and dry air are often very large and abrupt. In general, these characteristics agree with typical daily SSM/I observations (not shown).

Figure 6 illustrates the temporal development of the tropospheric humidity field over the western Pacific warm pool for a 1-month period. It is evident that the transients are of an advective nature, with the most 
free tropospheric humidity 21 Dec 1982

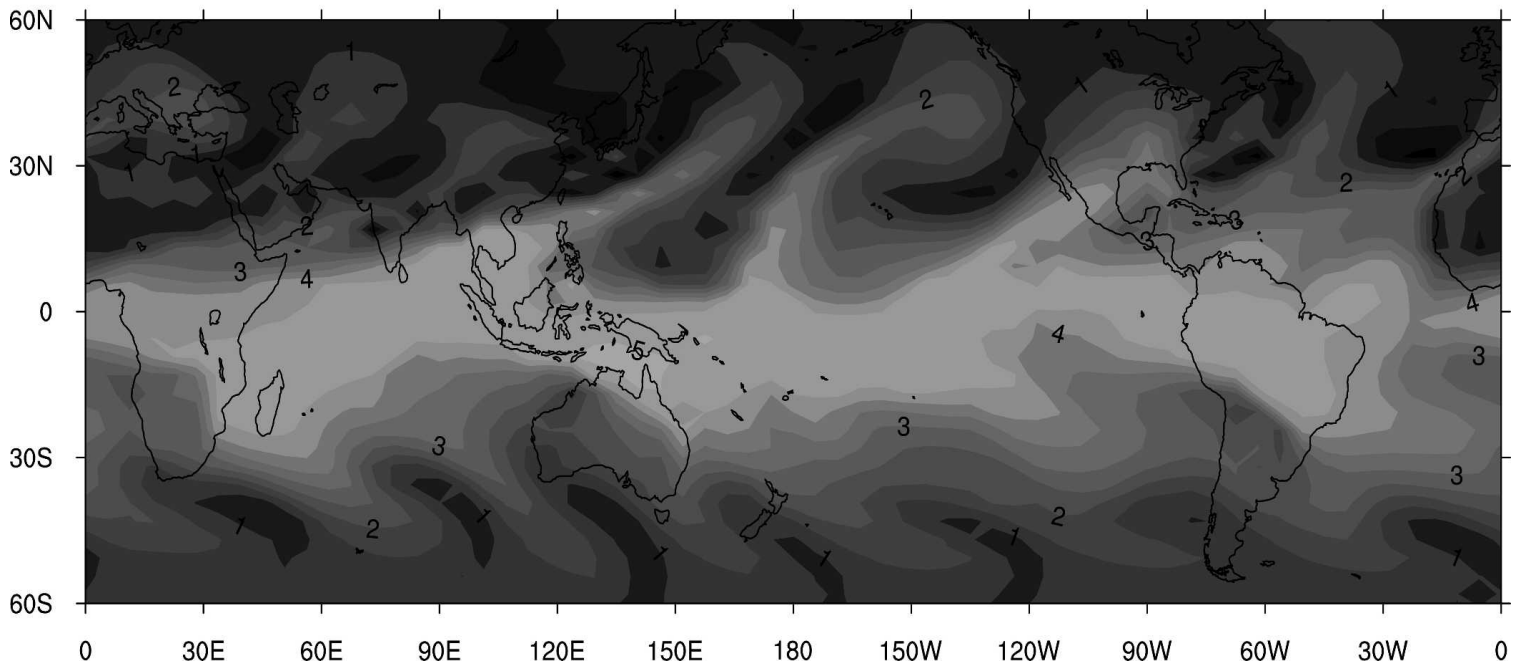

FIG. 5. Example of the free-tropospheric humidity field $\hat{q}_{1}\left(\mathrm{~g} \mathrm{~kg}^{-1}\right)$ for a 1-day average on a December day in 1982, of the model run with $\tau_{\mathrm{sh}}=1 \times 10^{5} \mathrm{~s}$. The black line labels indicate the value at the associated contour line.

intense activity at the northern side of the warm pool. The reason for this is the relatively close proximity of midlatitude disturbances to the convection zone in Northern Hemisphere winter, resulting in an intense interaction and exchange between the midlatitudes and the tropical belt in the warm pool (Lin et al. 2000).

Figure 7 a shows a latitude cross section of the freetropospheric humidity $\left(q_{1}\right)$ climatology. The location and season correspond to Fig. 6. The changes in freetropospheric humidity with $\tau_{\mathrm{sh}}$ are most significant at the northern side of the warm pool (about $-2 \mathrm{~g} \mathrm{~kg}^{-1}$ ).
To quantify the relative importance of advective humidity transients in this process, the total advective humidity tendency is split up into a mean and transient part:

$$
(\mathbf{v} \cdot \nabla q)_{\text {trans }}=\overline{\mathbf{v} \cdot \nabla q}-\overline{\mathbf{v}} \cdot \nabla \bar{q}
$$

The overbar represents a climatological average as a function of season. The transient part (left-hand side) is obtained as the residual of the two terms of the righthand side, and represents all product terms including a perturbation term. Figures $7 b, c$ illustrate that transients a)

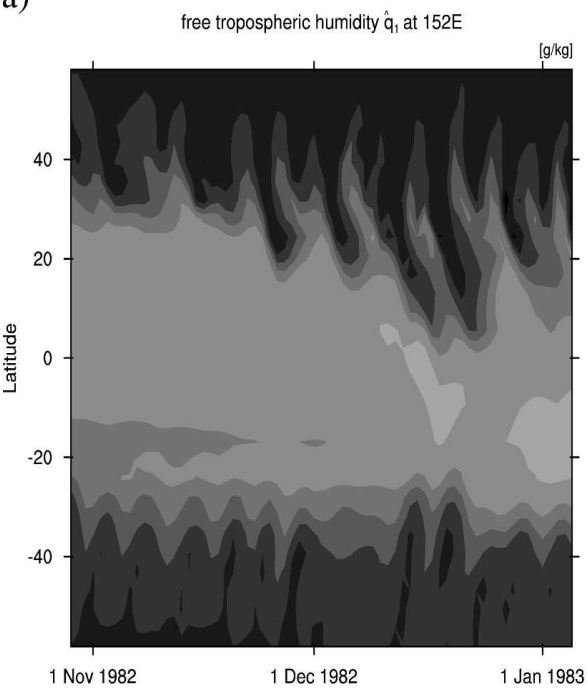

b)

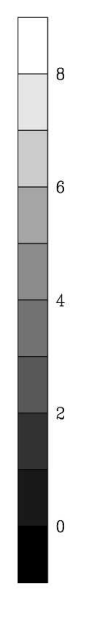

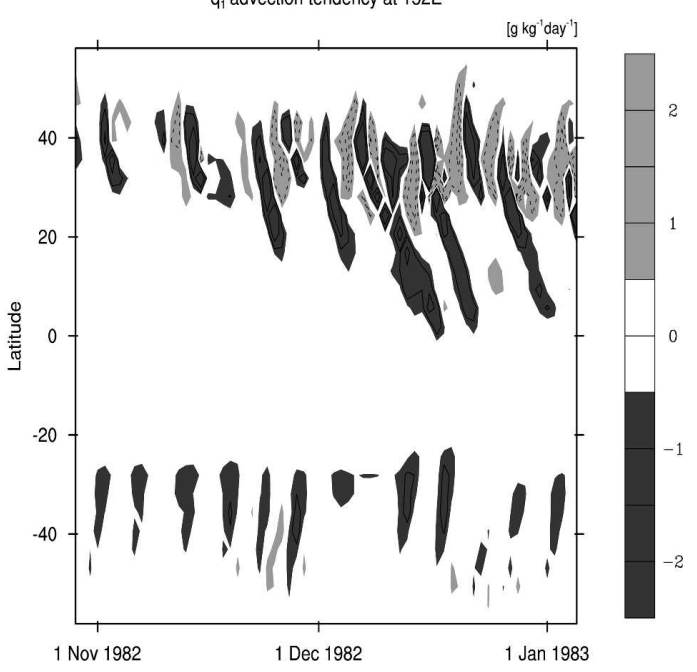

FIG. 6. Latitude-time plots of (a) free-tropospheric humidity $\hat{q}_{1}\left(\mathrm{~g} \mathrm{~kg}^{-1}\right)$ and (b) the free-tropospheric humidity tendency by advection $\left(\mathrm{g} \mathrm{kg}^{-1} \mathrm{day}^{-1}\right)$, at longitude $152^{\circ} \mathrm{E}$ for the period of November-December in 1982, for the model run with $\tau_{\mathrm{sh}}=1 \times 10^{5} \mathrm{~s}$. 
a)

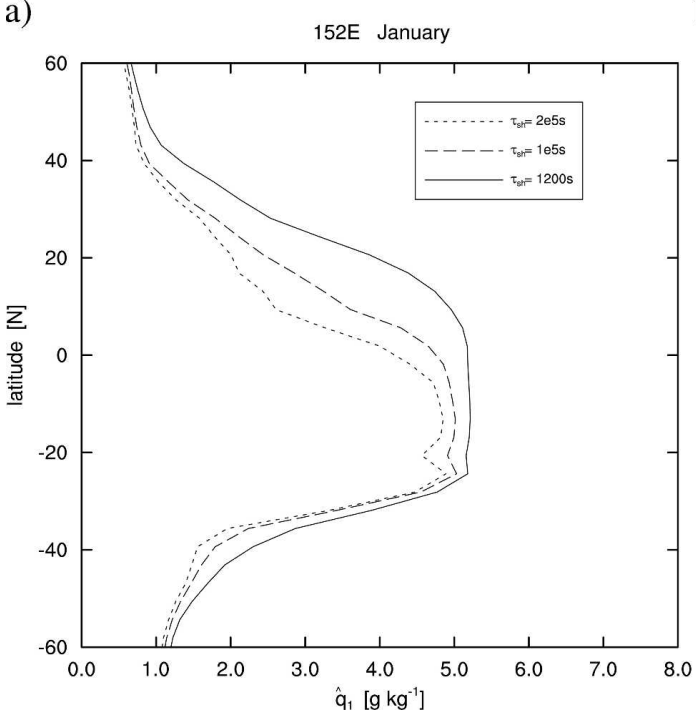

b)

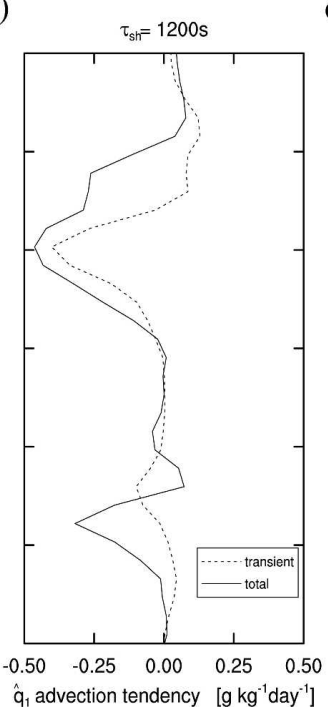

c)

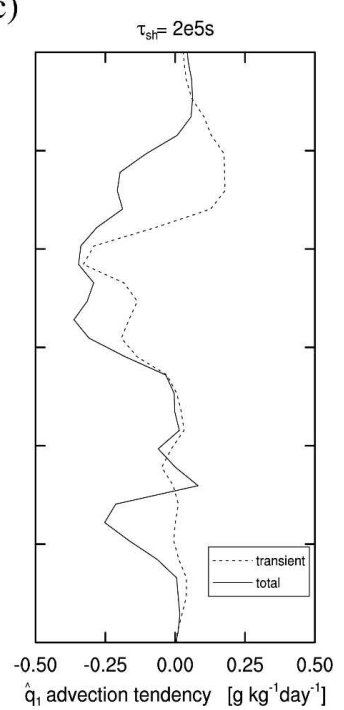

FIG. 7. (a) Meridional cross section in the western Pacific at longitude $151^{\circ} \mathrm{E}$ through the free-tropospheric humidity field $\hat{q}_{1}$. Each line represents a separate run, with $\tau_{\mathrm{sh}}=1.2 \times 10^{3} \mathrm{~s}, 1 \times 10^{5} \mathrm{~s}$, and $2 \times 10^{5} \mathrm{~s}$, respectively. (b), (c) The same cross section through the free-tropospheric advective tendency field of the runs with (b) $\tau=1200$ $\mathrm{s}$ and (c) $\tau=2.0 \times 10^{5} \mathrm{~s}$. Here the solid line represents the total advection $\overline{\mathbf{v} \cdot \nabla}$, while the dotted line represents the advection by transients; see (20).

contribute significantly to the total humidity advection, peaking roughly where the meridional humidity gradient is strongest. The sign and location of the transient advection climatology in Fig. 7 corresponds well with the behavior of the individual events captured in Fig. 6, with dry plumes reducing moisture in the warm pool edges and moist plumes exporting moisture to the subtropics.

Comparing Figs. $7 \mathrm{~b}, \mathrm{c}$ shows that with weakening shallow cumulus (increasing $\tau_{\mathrm{sh}}$ ) dry transients reach farther into the tropical humidity belt for two main reasons. First, the advected subtropical air above the $\mathrm{ABL}$ tends to be drier to begin with, due to changes in the balance of subsidence drying versus shallow convective moistening schematized in Fig. 8. Second, shallow convection is less effective in moistening them as they move equatorward over warmer water. The effect of a dry intrusion is to dampen deep convection at the edges of the convecting zones, at least until the tropospheric moisture is restored to such a degree that deep convection can occur. This argument is supported by the frequency of occurrence of congestus peaking at the edges of the deep convective ITCZ (see Fig. 9). Furthermore, the $2 \mathrm{~g} \mathrm{~kg}^{-1}$ reduction of tropospheric humidity $\hat{q}_{1}$ in the edges of the ITCZ can be compared to the sensitivity of $\left\langle Q_{c}\right\rangle$ to this parameter as dictated by moisture closure (5) seen in Fig. 3. This illustrates that this degree of tropospheric drying is capable of significantly reducing precipitation in this model. Although the incoming transients are temporary disturbances that typically last only a few days, they thus have a significant net impact on the climatology of convective precipitation at these locations.

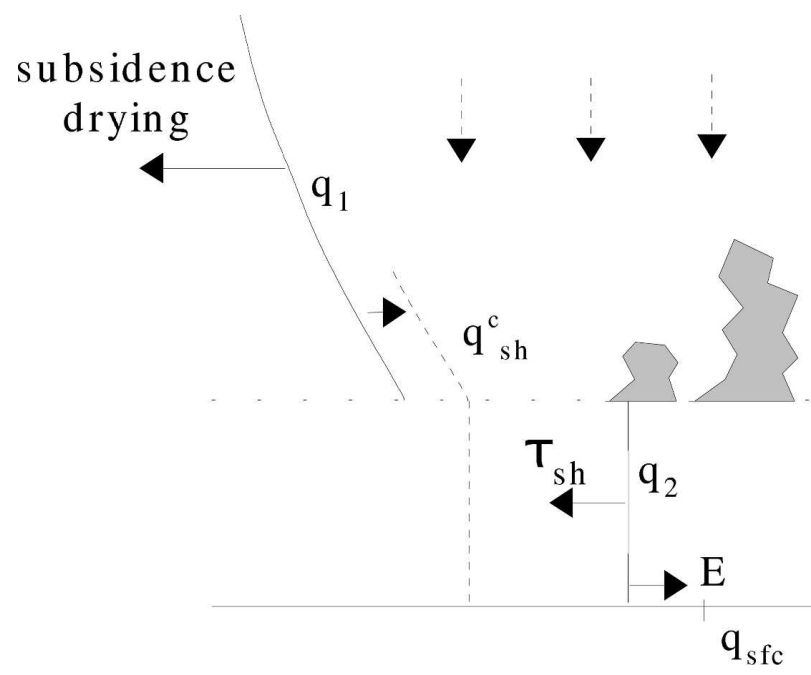

FIG. 8. Processes acting on humidity in the $2 \mathrm{BF}$ setup for nonprecipitating subsidence situations. Each process is represented by a solid arrow. The symbols are explained in the text. The dotted line represents the shallow adjustment humidity profile $q_{\mathrm{sh}}^{c}$. While surface evaporation $E$ acts to moisten the boundary layer, shallow convection $\tau_{\mathrm{sh}}$ acts to dry it out. In the free troposphere, shallow convection moistens while large-scale subsidence (dotted arrows) dries. 


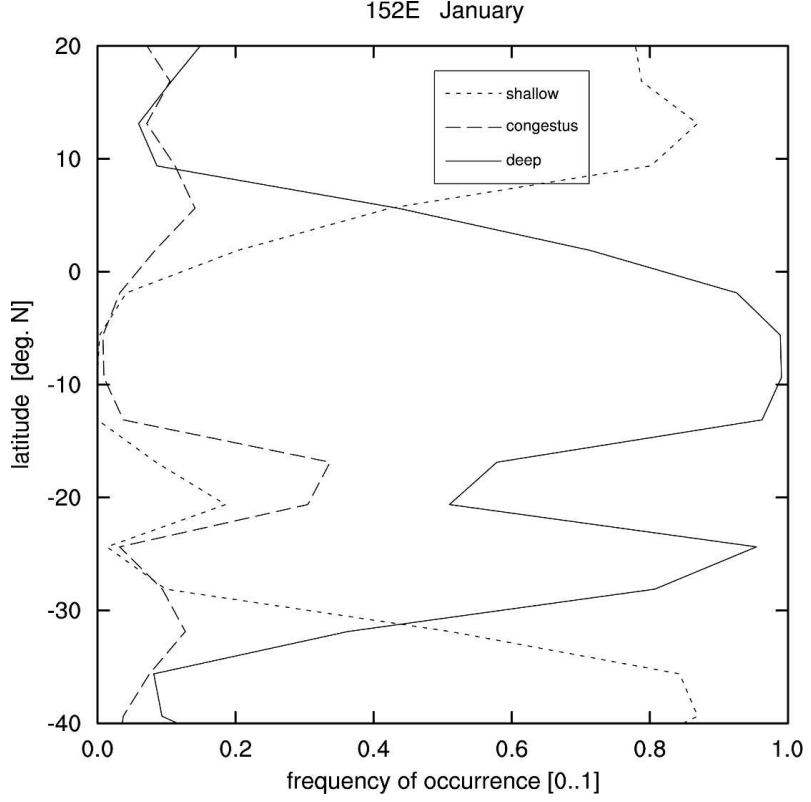

FIG. 9. Monthly mean climatological frequency of occurrence of the three modes of convection in January, on a cross section at $152^{\circ} \mathrm{E}$ for $\tau_{\mathrm{sh}}=2 \times 10^{5} \mathrm{~s}$

We note that dry advection by the mean wind, the second term on the rhs of (20), has similar effects at the margins of the convection zones. We focus on the transient contribution here because it is substantial, slightly more complex, and the contribution of the mean moisture advection in related mechanisms has been more clearly addressed than that of the transients (e.g., Neelin et al. 2003).

\section{Climate feedback mechanisms}

Figure $4 \mathrm{c}$ shows that, in contrast to the ITCZ edges, the precipitation rate has increased in its core axis. In other words, with reduced shallow cumulus (increased $\tau_{\text {sh }}$ ) the oceanic ITCZs get narrower but are at the same time intensified. Apparently, shallow cumulus convection affects tropical climate through more ways than just affecting horizontal humidity advection. To fully understand all elements of this tropical feedback mechanism, we now turn to the large-scale MSE budget.

\section{a. Moist static energy budgets}

The MSE is defined as

$$
h=T+q+\phi
$$

(e.g., Yanai et al. 1973), where $\phi$ is geopotential height. The MSE budget equation is obtained by adding the prognostic equations for $T$ and $q$. For our purposes we consider the perturbation equation only, which can be written as

$$
\begin{aligned}
\left\langle\partial_{t}(T+q)\right\rangle^{\prime} & +\left\langle\mathcal{D}_{h}(T+q)\right\rangle^{\prime}+\left(M \nabla \cdot \mathbf{v}_{1}\right)^{\prime} \\
& =\left(F_{\mathrm{rad}}^{\prime}+H^{\prime}+E^{\prime}\right) .
\end{aligned}
$$

The angle brackets \langle\rangle here denote the vertical column integral, and the prime ' denotes the perturbation from the reference run, in this case chosen to be the run with the smallest time scale $\tau_{\mathrm{sh}}=1200 \mathrm{~s}$. The time derivative is $\partial_{t}, \mathcal{D}_{h}$ is the horizontal advection/diffusion operator, and $M \boldsymbol{\nabla} \cdot \mathbf{v}_{1}$ is the vertically integrated vertical advection term, written in terms of the gross moist stability $M$ (Neelin and Held 1987) and the large-scale divergence projected on the baroclinic mode $\boldsymbol{\nabla} \cdot \mathbf{v}_{1}$. By convention, the latter is positive for low-level convergence. The net static stability for convergence of large-scale motions $M$ can be interpreted as the work that the large-scale circulation has to do in order to overcome the vertical dry static energy gradients, taking into account partial cancellation by heating associated with moisture convergence. Units here follow Neelin and $\mathrm{Su}$ (2005). The right-hand side of (22) is the net flux of energy into the column $\left(F_{\text {net }}\right)$, where $F_{\text {rad }}$ is the net radiative flux [both longwave (LW) and shortwave (SW)]; and $E$ and $H$ are the surface latent and sensible heat fluxes, respectively. Equation (22) is a useful tool to express the impacts of any process affecting the column-average thermodynamics on the large-scale circulation.

Figure 10 shows the individual terms in (22) at two different locations, one in the Tropics and one in the subtropics. In the core of the convection zone the advection term $\left\langle\mathcal{D}_{\mathrm{h}}(T+q)\right\rangle^{\prime}$ is negligible compared to two dominating terms:

$$
\left(M \nabla \cdot \mathbf{v}_{1}\right)^{\prime} \approx F_{\text {net }}^{\prime},
$$

while in the subtropics and the margins of the convection zones advection must be included. Expanding the perturbation term $\left(M \boldsymbol{\nabla} \cdot \mathbf{v}_{1}\right)^{\prime}$ in the steady-state form of (22) into individual perturbations $M^{\prime}$ and $\left(\boldsymbol{\nabla} \cdot \mathbf{v}_{1}\right)^{\prime}$, the change in large-scale convergence can be written as

$$
\left(\boldsymbol{\nabla} \cdot \mathbf{v}_{1}\right)^{\prime}=\left(\boldsymbol{\nabla} \cdot \mathbf{v}_{1}\right)_{\text {no-adv }}^{\prime}+\frac{\left\langle\mathcal{D}_{h}(T+q)\right\rangle^{\prime}}{M},
$$

where the subscript "no-adv" refers to the part of $\left(\boldsymbol{\nabla} \cdot \mathbf{v}_{1}\right)$ ' that can be explained from balance (23):

$$
\left(\boldsymbol{\nabla} \cdot \mathbf{v}_{1}\right)_{\mathrm{no-adv}}^{\prime} \approx \frac{F_{\mathrm{net}}^{\prime}-M^{\prime} \boldsymbol{\nabla} \cdot \mathbf{v}_{1}^{\mathrm{ctl}}}{M^{\mathrm{ctl}}+M^{\prime}} .
$$

Here superscript "ctl" refers to the control run $\left(\tau_{\mathrm{sh}}=\right.$ $1200 \mathrm{~s})$. This equation gives the changes in large-scale 
a)

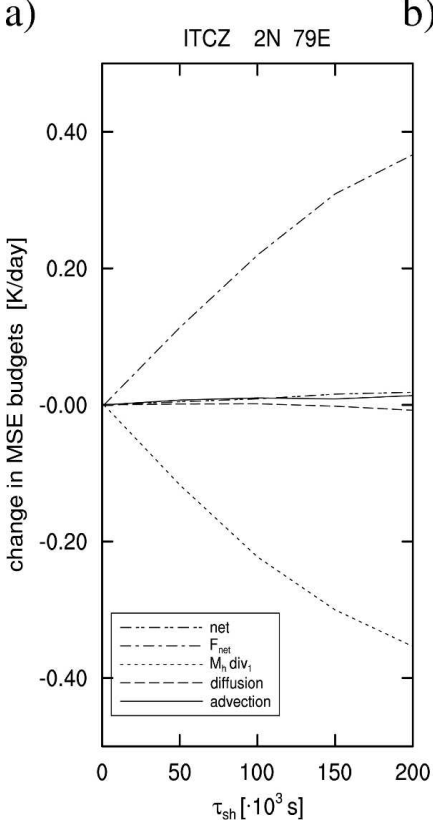

b)

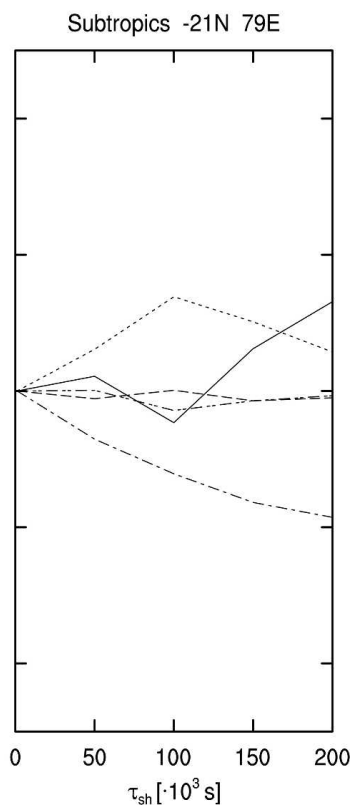

FIG. 10. The change of the moist static energy budgets compared to the $\tau_{\mathrm{sh}}=1200 \mathrm{~s}$ run as a function of $\tau_{\mathrm{sh}}$, at different locations in the Indian Ocean. A location (left) inside the convection zone and (right) just south of the convection zone. The acronyms refer to the terms in (22).

circulation associated with changes in surface fluxes, radiative fluxes, column-integrated moisture, and moist static stability. The terms with $M^{\prime}$ were labeled by Chou and Neelin (2004) as the M-prime mechanism. The standard $F_{\text {net }}^{\prime}$ term is important both inside and outside the convection zones (see Fig. 10).

Figure 11 shows the change of large-scale divergence in the QTCM and according to (25) in the Indian Ocean ITCZ where (25) applies well, and at a subtropical point where advection becomes important as $\tau_{\text {sh }}$ increases. Figure 12 shows maps of the divergence change $\boldsymbol{\nabla} \cdot \mathbf{v}_{1}$ as diagnosed in the QTCM and as calculated from (25). Assumption (23) has great validity in the Tropics. Figure 13 shows global maps of the terms contributing to $\left(\boldsymbol{\nabla} \cdot \mathbf{v}_{1}\right)^{\prime}$. While in the convection zones the $F_{\text {net }}^{\prime}$ term clearly dominates, the advection term cannot be neglected in the subtropics (also see Fig. 10b), especially in the margins of the convection zones.

In the convection zones over the continents few increases in convergence are seen. The reason for this is that $F_{\text {net }}^{\prime}$ is small as a result of the small heat capacity of the land, yielding zero net surface flux contribution. Second, Fig. 12b also shows that the continental reductions in convergence are not well captured by (25), because the horizontal humidity advection term (Fig. 13c) causes these.

a)

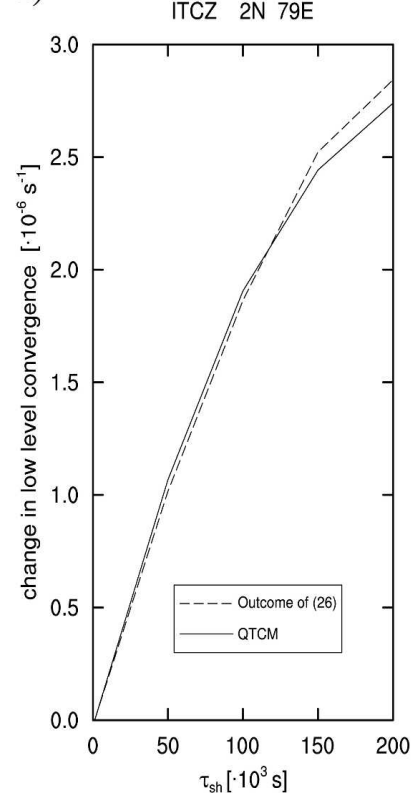

b)

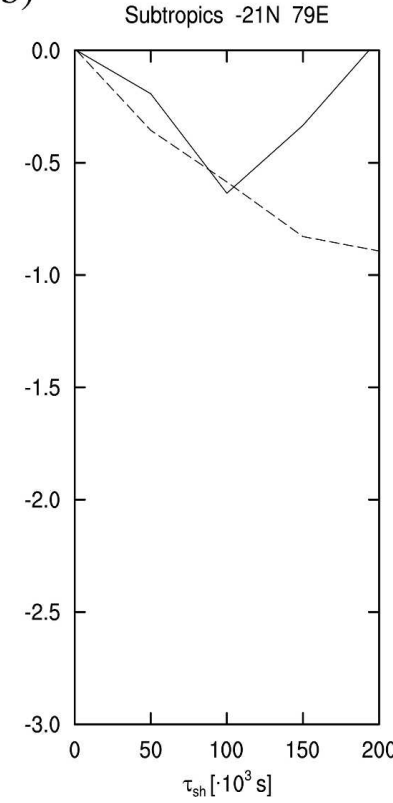

FIG. 11. The change of the large-scale low-level convergence (or upper-level divergence), both model result and calculated using the simplified relation (25), which omits advection.

\section{b. Net energy flux budgets}

The analysis in the previous section links the changes in large-scale convergence to changes in the net influx of energy into the atmospheric column. Next, a decomposition of $F_{\text {net }}^{\prime}$ is made into separate processes to determine which ones dominate. Figure 14b illustrates that in the subtropics $F_{\text {net }}^{\prime}$ is always dominated by surface evaporation. In this area shallow cumulus is the dominant type of convection. By reducing its intensity, vertical redistribution of humidity is weakened, moistening the atmospheric mixed layer, reducing the surface evaporation, and drying the lower free troposphere.

In the core of the tropical convection zones, the convection in the QTCM is always done by the deep convection scheme (see Fig. 9). As a consequence, any change in $\tau_{\mathrm{sh}}$ does not have a local effect there, and impacts must occur through some indirect feedback mechanism. Figure 14a shows that, in contrast to the subtropics, in the convection zones two other processes are almost as important as surface evaporation in the MSE budget: the surface sensible heat flux $H^{\prime}$ and the LW radiative flux $F_{\mathrm{LW}}^{\prime}$. These terms suggest that a temperature change plays a role here, which is confirmed by Fig. 15. The drop in tropically averaged temperature in the latitude band between $35^{\circ} \mathrm{S}$ and $35^{\circ} \mathrm{N}$ is about $1-2$ $\mathrm{K}$. The similar sign and magnitude of these two terms in the subtropics reflects that this cooling is not confined 
a)
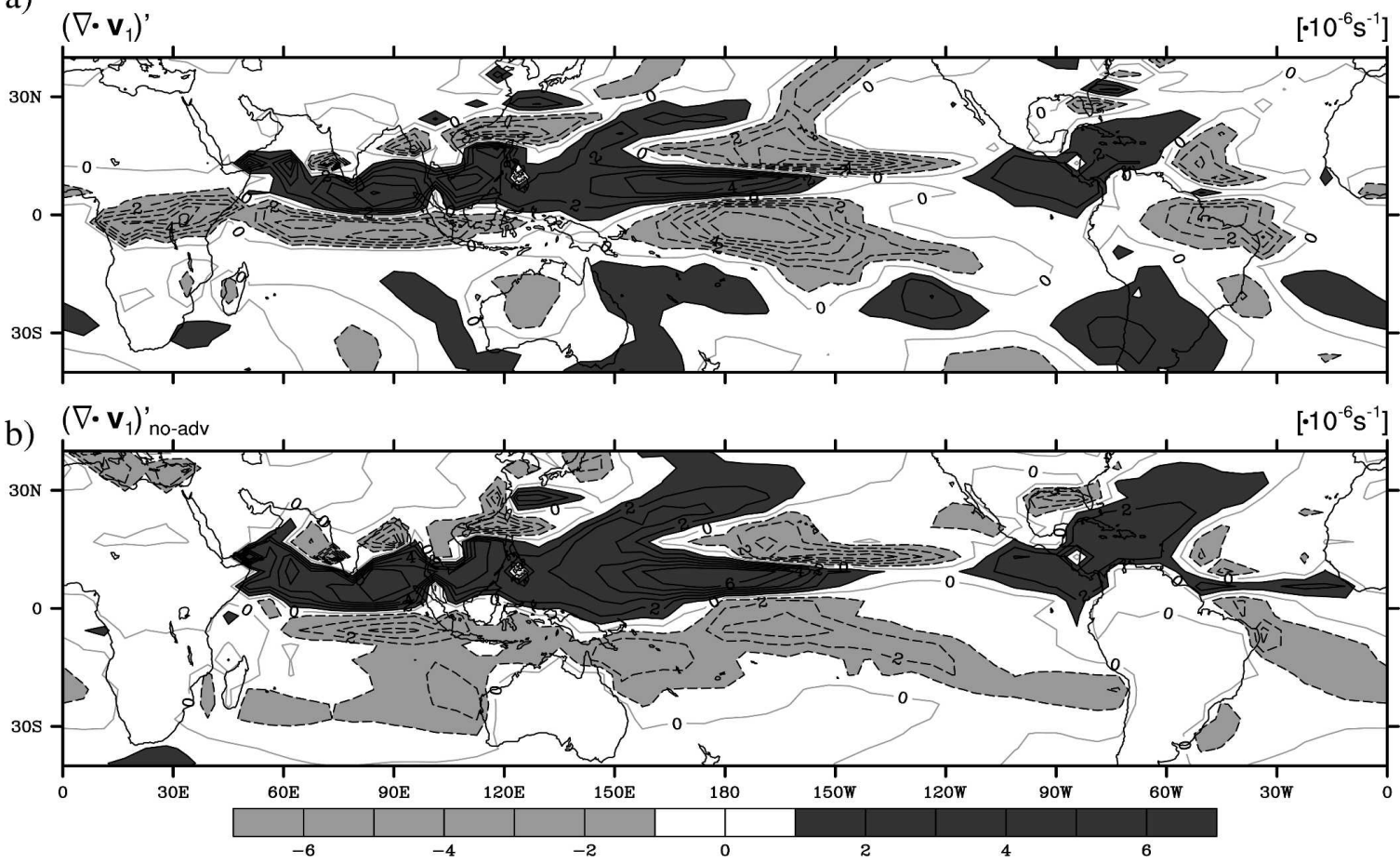

FIG. 12. Global maps of the low-level convergence change $(\boldsymbol{\nabla} \cdot \mathbf{v})^{\prime}$ between the $\tau_{\mathrm{sh}}=200000 \mathrm{~s}$ and $\tau_{\mathrm{sh}}=1200 \mathrm{~s}$ run, both model and that predicted by (25)

to the ITCZ but manifests itself throughout a large area via equatorial wave dynamics, as expected (Neelin and Held 1987; Sobel and Bretherton 2000).

\section{c. Convective heating}

There are two ways to see the balances that lead to the temperature drop. One is that, averaged over the Tropics, the transport terms in the MSE budget in (22) tend to become small, so the reduction in evaporation seen in Fig. 4b must be balanced by a reduction in LW radiation loss to the column (see Fig. 14), necessitating a temperature reduction. Alternately, we can consider the temperature equation, including the convective heating term $Q_{c}$ :

$$
\begin{aligned}
{\left[\left\langle\partial_{t} T\right\rangle^{\prime}\right] } & +\left[\left\langle\mathcal{D}_{T} T\right\rangle^{\prime}\right]+\left[\left(M_{s} \boldsymbol{\nabla} \cdot \mathbf{v}_{1}\right)^{\prime}\right] \\
& =\left[\left\langle Q_{c}\right\rangle^{\prime}+H^{\prime}+F_{\mathrm{LW}}^{\prime}+F_{\mathrm{SW}}^{\prime}\right] .
\end{aligned}
$$

Here the brackets [] denote the area average over the latitude band between $35^{\circ} \mathrm{S}$ and $35^{\circ} \mathrm{N}$. The reason for this area averaging here is that the temperature change acts throughout the whole Tropics, and therefore also the LW radiation and surface heat flux feedbacks: a closed energy budget requires an average over the whole area that is affected. The precipitation rate is represented in this equation by the vertically integrated convective heating tendency $\left\langle Q_{c}\right\rangle$.

Figure 16a shows that the change in convective heating, corresponding to a reduction in tropically averaged precipitation, is balanced largely by a reduction in LW cooling. Figure $16 \mathrm{~b}$ shows a further breakup of the change of the net LW flux into contributions by temperature, moisture, surface temperature, and cloud fraction (NZ00; Su et al. 2003). The main contributors are the lower tropical temperature, as well as a subtropical net moisture greenhouse effect due to the freetropospheric humidity drop.

\section{d. Response of the large-scale dynamics}

At this point some conclusions can be drawn regarding the feedback mechanism that is at work. If subtropical shallow cumulus convection is reduced, the tropically averaged precipitation decreases through tropospheric advection of drier air into the ITCZ area. The associated reduction in convective heating triggers a temperature drop of about 1-2 $\mathrm{K}$ throughout a large area of the Tropics. In turn, this causes compensating changes in LW radiation.

Finally, we return to the combined effect of all these on the overall tropical energy budget, considering the MSE budget in Eq. (22) averaged over $35^{\circ} \mathrm{S}-35^{\circ} \mathrm{N}$. Fig- 
a)

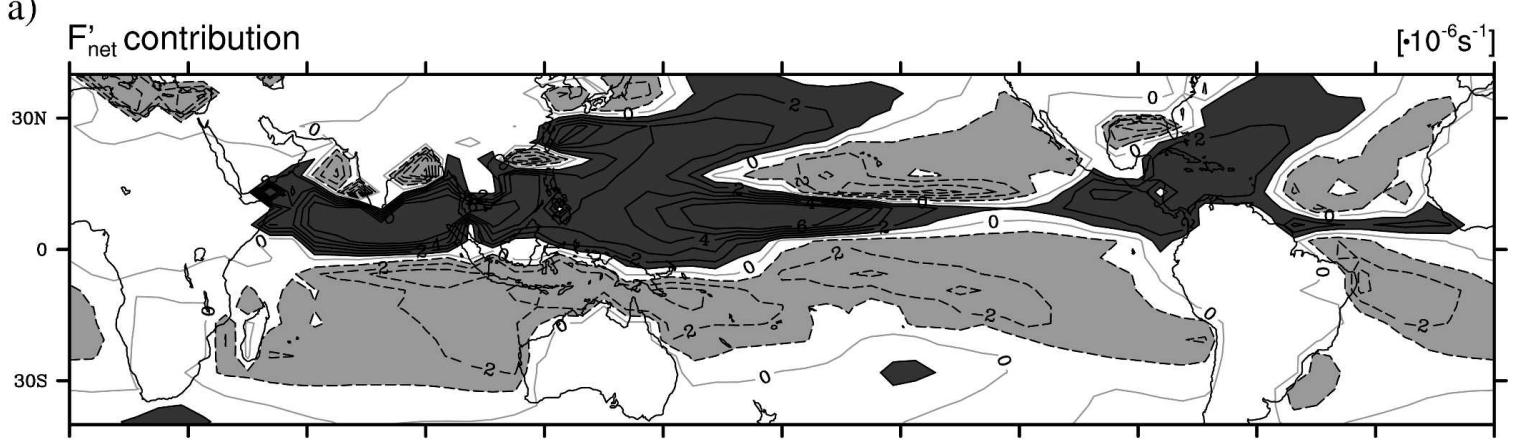

b) M' contribution
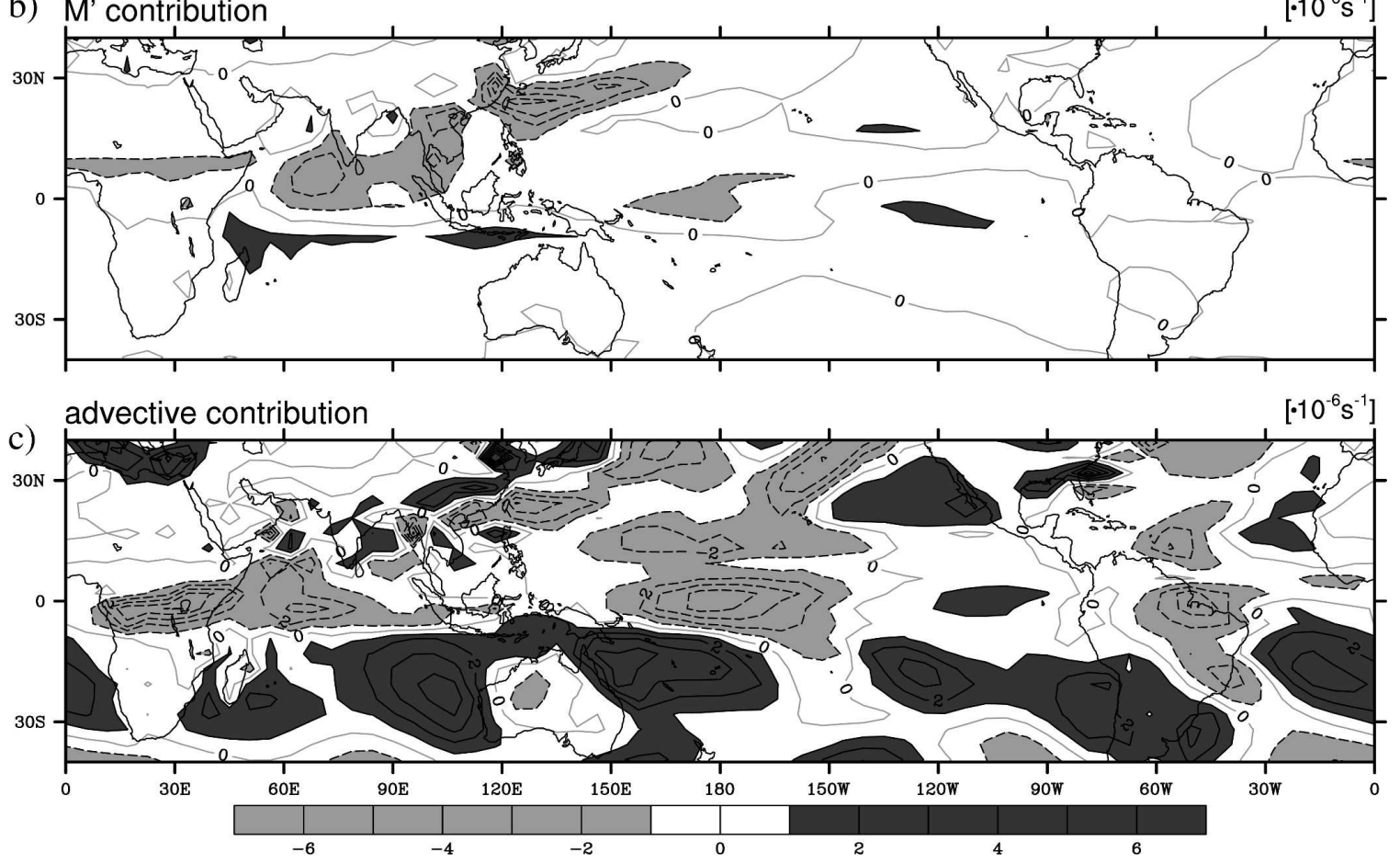

FIG. 13. The contributions to convergence change $(\boldsymbol{\nabla} \cdot \mathbf{v})^{\prime}$ as plotted in Fig. 12a by (a) $\left[F_{\text {net }}^{\prime} /\left(M^{\text {ctl }}+M^{\prime}\right)\right],(\mathrm{b})\left[-M^{\prime} \nabla \cdot \mathbf{v}^{\mathrm{ctl}} /\left(M^{\mathrm{ctl}}+\right.\right.$ $\left.\left.M^{\prime}\right)\right]$, and (c) $\left(\left\langle D_{h} q\right\rangle^{\prime} / M\right)$. Together (a) and (b) make up the nonadvective contribution [see (25)].

ure $16 \mathrm{c}$ shows that decreased evaporation is indeed largely balanced by the reduction in LW cooling plus a small increase in the surface sensible heat flux. Comparing the value of the change in evaporation to the change in convective heating as plotted in Fig. 16a, we see that the tropical average precipitation change is balanced by the evaporation change.

These changes in the net energy budget of the atmosphere represent an important shift in the climatological balance between physical processes. The main loss of energy input is caused by the reduced surface evaporation, dominated by the subtropics, and directly caused by the weaker shallow convection. Eventually, through many processes, this gets compensated by an enhanced input of energy through the LW radiative budget. On the way, the thermodynamic state of the tropical climate has changed significantly, with temperature changes of $1-2 \mathrm{~K}$ and water vapor path changes of up to $10 \mathrm{~mm}$.

From the point of view of the perturbation in Eqs. (24)-(25), the temperature drop throughout the Tropics implies a positive $F_{\mathrm{LW}}^{\prime}$ and $H^{\prime}$ everywhere. In the core of the convection zones this causes a positive $F_{\text {net }}^{\prime}$ (Figs. 13a and 14a). As the column water vapor path has not changed much in these areas, $M$ is rather constant. The horizontal moisture advection can be neglected in the central parts of the convection zone. Through (25) this results in a stronger low-level convergence, accompanied by heavier precipitation and an associated surface evaporation increase. 
a)

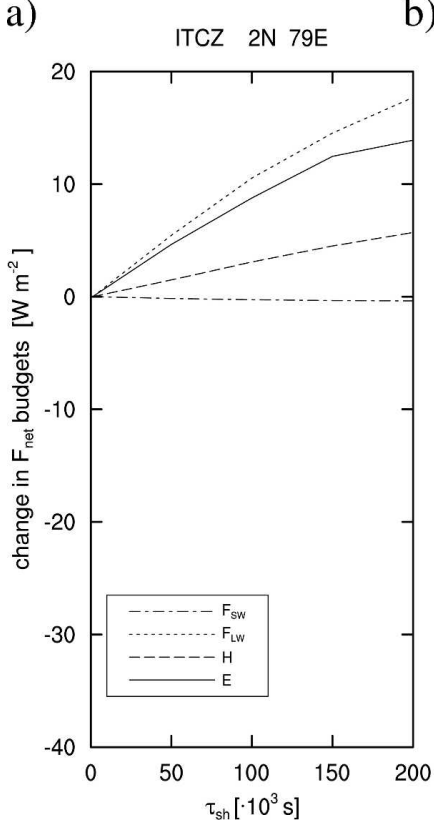

b)

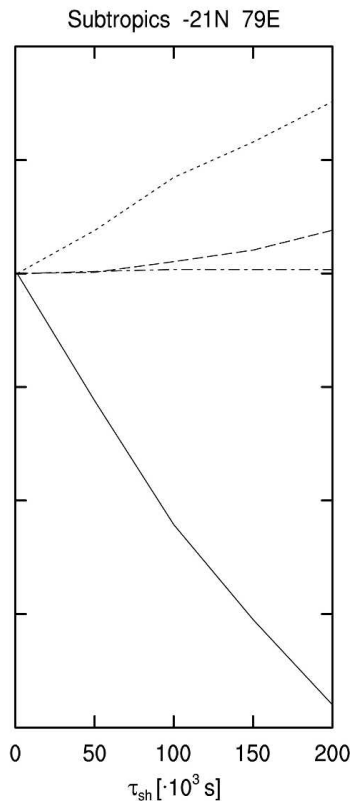

FIG. 14. Breakdown of $F_{\text {net }}^{\prime}$ into separate processes.

In the subtropics and the edges of the ITCZ, things are different. There $F_{\text {net }}^{\prime}$ is negative, as it is dominated by the evaporation decrease due to the more humid atmospheric mixed layer as a result of the reduced shallow convective mixing (Fig. 14b). The associated strong decrease in subtropical water vapor path causes the $M^{\prime}$ term in (25) to be no longer negligible compared to $F_{\text {net }}^{\prime}$ (Fig. 13b). Furthermore, strong moisture gradients cause substantial drying by advection in the margins of the convection zones (Fig. 13c). Through (24) this results in less strong low-level convergence at the edges, accompanied by a lower precipitation rate.

Summarizing this analysis, the whole chain of feedbacks couples the intensity of shallow convection in the subtropics to the width and intensity of the ITCZ. The results show that this impact can be significant, with precipitation rate changes of up to $4 \mathrm{~mm} \mathrm{day}^{-1}$. The key elements in this chain of feedbacks is the sensitivity of deep convection to free-tropospheric humidity, on the one hand, and the globalization of the compensating response on the other. Thus, the $\mathrm{Cu}-q$ throttle launches the entire chain.

\section{Oceanic mixed layer case}

In the model experiments discussed so far the SST was prescribed. In reality, the oceanic mixed layer temperature is affected by the atmosphere through the net energy flux at the ocean surface. The SST adjusts in such a way that the net heat flux is reduced except in

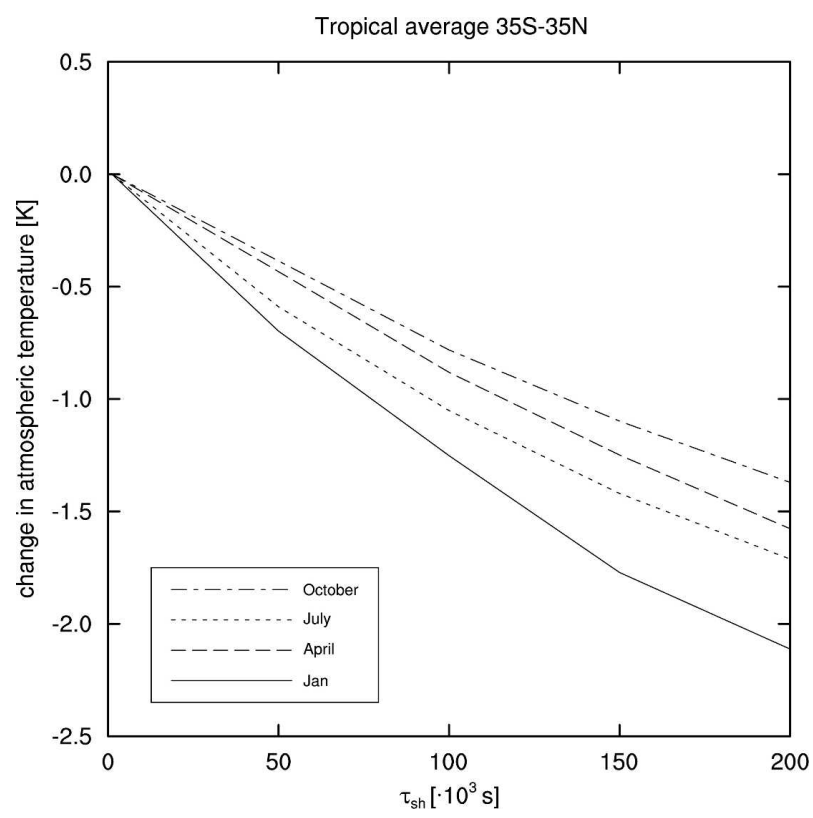

FIG. 15. The change of the tropically averaged temperature during the sensitivity test.

regions where seasonal heat storage in the ocean is large. Examples are the areas that are only covered by an ITCZ during parts of the year, associated with its meridional seasonal migration.

To evaluate the impacts of an interactive SST, the same series of runs is performed but now including an interactive oceanic mixed layer of 50-m depth, as described by Su et al. (2001). The $Q$ flux, representing the divergence of ocean heat transport, is obtained from a reference run using the method of Hansen et al. (1988). This particular $Q$-flux climatology is assumed to be independent of $\tau_{\mathrm{sh}}$, and is applied in all the runs.

Figure 17a shows the annual mean SST response, as a result of the increase of $\tau_{\mathrm{sh}}$ from 1200 to $200000 \mathrm{~s}$. For increasing $\tau_{\mathrm{sh}}$, the SST warms by about $2 \mathrm{~K}$ in the subtropics, as a result of the reduced surface evaporation that dominates the surface net heat flux in those areas. The SST response is largest where shallow cumulus convection occurs most frequently in the model (see Fig. 17b). This illustrates that the SST response acts to remove the surface energy imbalance that is a direct result of the reduced surface evaporation associated with the surpressed vertical transport by marine shallow cumulus convection.

The magnitude of the SST response makes the impact of this feedback mechanism comparable to other processes involved in ocean-atmosphere interaction. This study focuses on one specific impact of subtropical boundary layer clouds (i.e., vertical transport by shallow cumulus), and not all possible impacts. Other feed- 
a)

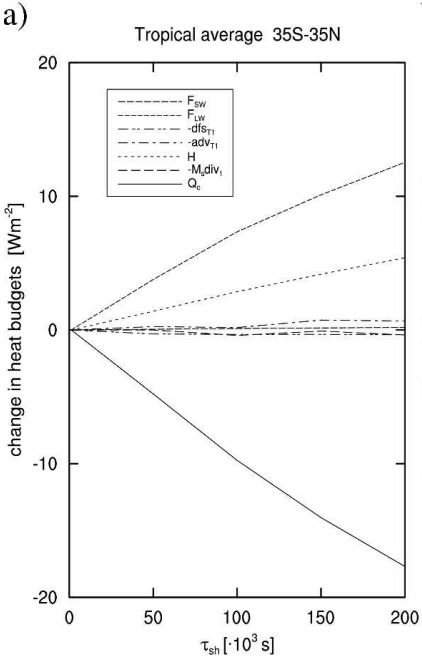

b)

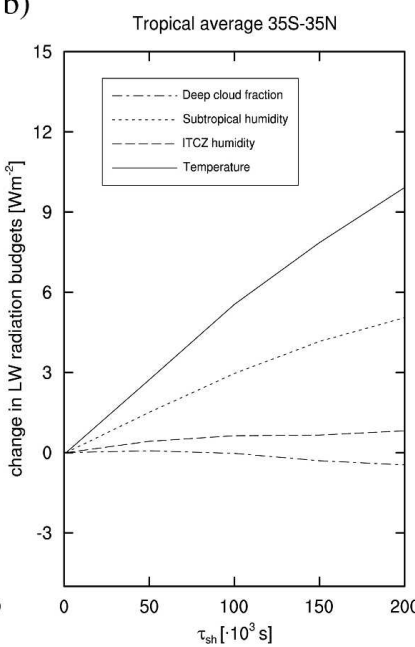

c)

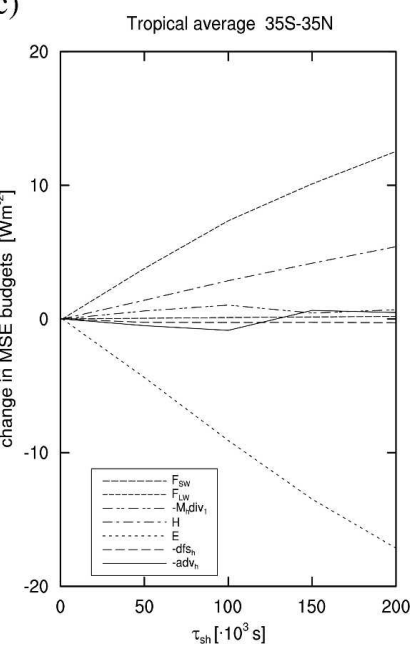

FIG. 16. Changes in the tropically averaged $\left(35^{\circ} \mathrm{S}-35^{\circ} \mathrm{N}\right)$ budgets of (a) heat, (b) the LW radiative flux, and (c) MSE. Changes as a function of $\tau_{\mathrm{sh}}$ are relative to the $\tau_{\mathrm{sh}}=1200 \mathrm{~s}$ control run. The acronyms are explained in the text. The humidity contribution to the LW radiation budget in (b) is broken down into two terms representing the areas separated by the precipitation isoline of $200 \mathrm{~W} \mathrm{~m}^{-1}$. These can be thought of as the convection zone and the subtropics.

back mechanisms not explicitly represented in this QTCM version might counteract the SST warming resulting from the shallow cumulus humidity throttle feedback. The most important example is arguably the direct radiative impact of subtropical low clouds on climate (e.g., Wang et al. 2004; McCaa and Bretherton 2004). Low-level cloudiness reduces the SW net radiation at the surface, tending to cool the SST.

The relevance of the results of this study for oceanatmosphere interaction is therefore that they reveal the existence of a second, more indirect impact of subtropical low clouds on SST, which counteracts their direct radiative impact. We suggest that the role of this shallow cumulus $\mathrm{Cu}-q$ feedback is important to evaluate in assessing the processes affecting subtropical SST in climate models, noting that it is large in regions where many models exhibit significant climate errors.

We now consider the comparison to the fixed-SST case used in previous sections. Apart from their direct relevance to numerical weather prediction models run with fixed SST, and their use in highlighting the atmospheric part of the shallow cumulus feedback mechanism, in certain conditions the results of the fixed SST experiments are indicative of the coupled system response. In the equinox seasons [March-May (MAM) and September-November (SON)] the strengthening of the ITCZ with reduced shallow cumulus weakens somewhat. Due to the adjustment of SST, the response in the surface heat flux and LW radiation budget are smaller compared to the fixed SST runs. However, in the solstice seasons [June-August (JJA) and Decem-
ber-February (DJF)], in those areas that have large seasonal heat storage, the SST does not adjust fast enough to counteract the atmospheric temperature change, and the ITCZ strengthening is comparable to the fixed SST runs (not shown).

\section{Discussion and conclusions}

In this study a simple framework for shallow cumulus convection is used to explore its impact on the tropical climate system. The introduction of an extra degree of freedom for humidity results in two new types of convection in the QTCM: in addition to deep convection, shallow cumulus and weakly precipitating cumulus congestus occur, both of which moisten the lower troposphere. Despite the simple formulation of the convection scheme, considerable sensitivity to free-tropospheric moisture is introduced, as found in cloudresolving models (Derbyshire et al. 2004). The model thus captures enough of the convective physics to assess first-order impacts on climate that could a priori be associated with the shallow cumulus humidity throttle mechanism. The decoupling of the atmospheric mixedlayer and tropospheric humidity also increases horizontal humidity transients in the QTCM.

The moist static energy (MSE) framework proves useful for studying the energetic constraints on climate feedback mechanisms. In this case, the changes in the net energy budget result from changes in the intensity of subtropical shallow convection. Shifts occur in MSE transport terms, and radiative and evaporative fluxes as 
a)

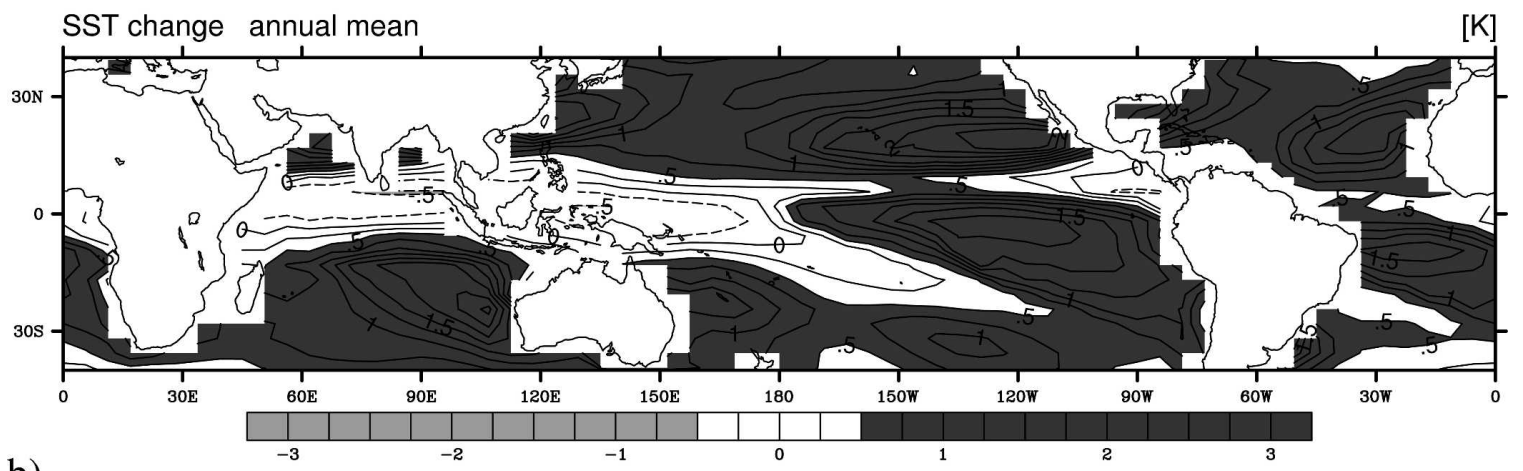

b)

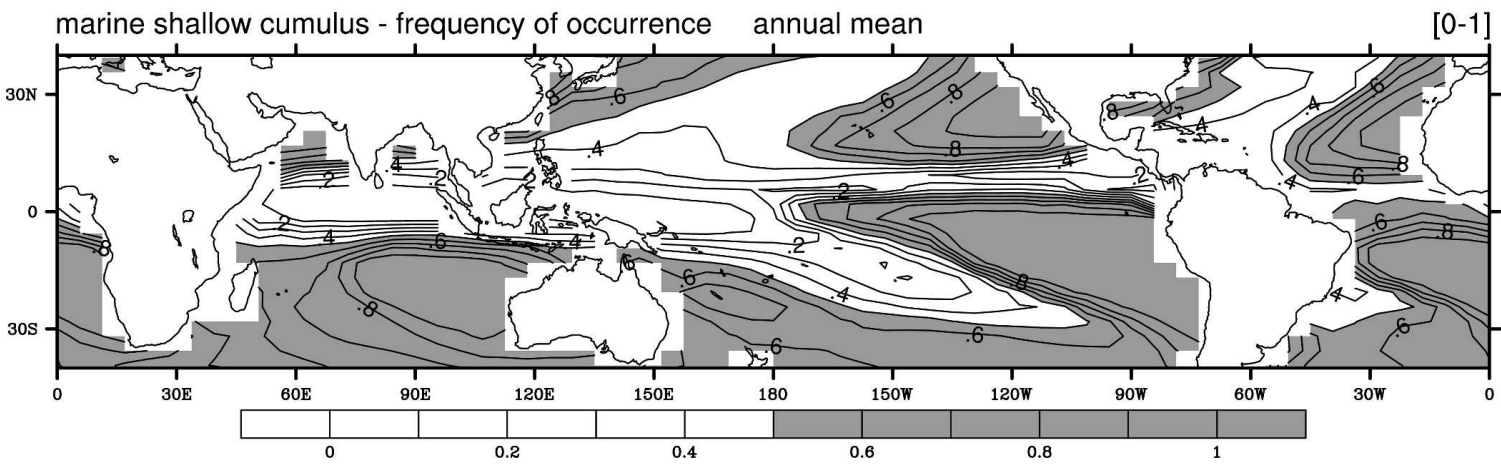

FIG. 17. (a) Change of annual mean SST between the $\tau_{\mathrm{sh}}=200000 \mathrm{~s}$ run relative to the $\tau_{\mathrm{sh}}=1200 \mathrm{~s}$ run, both with interactive oceanic mixed layer. (b) Annual mean frequency of occurrence (fraction of time) of marine shallow cumulus convection in the $\tau_{\mathrm{sh}}=200000$ s run. Note that in this simplified framework "shallow cumulus" covers all situations where no deep convection or congestus occurs.

the large-scale circulation adjusts to a new equilibrium in response to changes in shallow convection.

Figure 18 schematically summarizes these processes. Because an important step is the control over the supply of moisture to the convergence zones, we term this the shallow cumulus humidity throttle mechanism. Starting with the intensity of shallow convection in the subtropics, it ends with the width and strength of the oceanic ITCZs. When subtropical shallow cumulus convection is reduced (larger $\tau_{\mathrm{sh}}$ ), the PBL remains more humid, while the free troposphere gets significantly drier. Locally, this implies less surface evaporation. This loss of energy input into the atmosphere has to be compensated for, in one way or another. This adjustment occurs through a remote feedback mechanism. As the less humid lower-tropospheric air is advected equatorward, the precipitative convection at the edges of the oceanic ITCZs is suppressed through the sensitivity of deep convection to atmospheric humidity. This reduction in convective heating causes the temperature to decrease by a few kelvins throughout the whole Tropics. The associated strong reduction in atmospheric LW cooling and a somewhat increased surface heat flux act to enhance the net MSE forcing everywhere. While in the subtropics this compensates the initial evaporation decrease, this is not the case in the center of the convection zones, which then experience a positive $F_{\text {net }}^{\prime}$. Instead, the large-scale circulation adjusts by increasing the low-level convergence in the ITCZs. This is accompanied by a local increase in precipitation rate. Finally, the interactive ocean experiments show that in a coupled ocean-atmosphere system this feedback mechanism can lead to SST differences up to $2 \mathrm{~K}$ in subtropical descent regions, between cases with different shallow cumulus mixing time. This would tend to counteract the direct radiative impact of low subtropical clouds on SST.

The findings presented here provide more insight into the strong sensitivity of GCMs to shallow cumulus, as is frequently reported (e.g., Tiedtke et al. 1988; Slingo et al. 1994; Gregory 1997; Jakob and Siebesma 2003). The role of shallow convection in the climate system is twofold: (i) it transfers moisture from the PBL to the lower troposphere, affecting surface evaporation, and (ii) it controls the tropospheric moisture supply into the ITCZs, affecting their width and intensity. The magnitude of these impacts cannot be ignored in the global budgets of energy and water. For example, the 


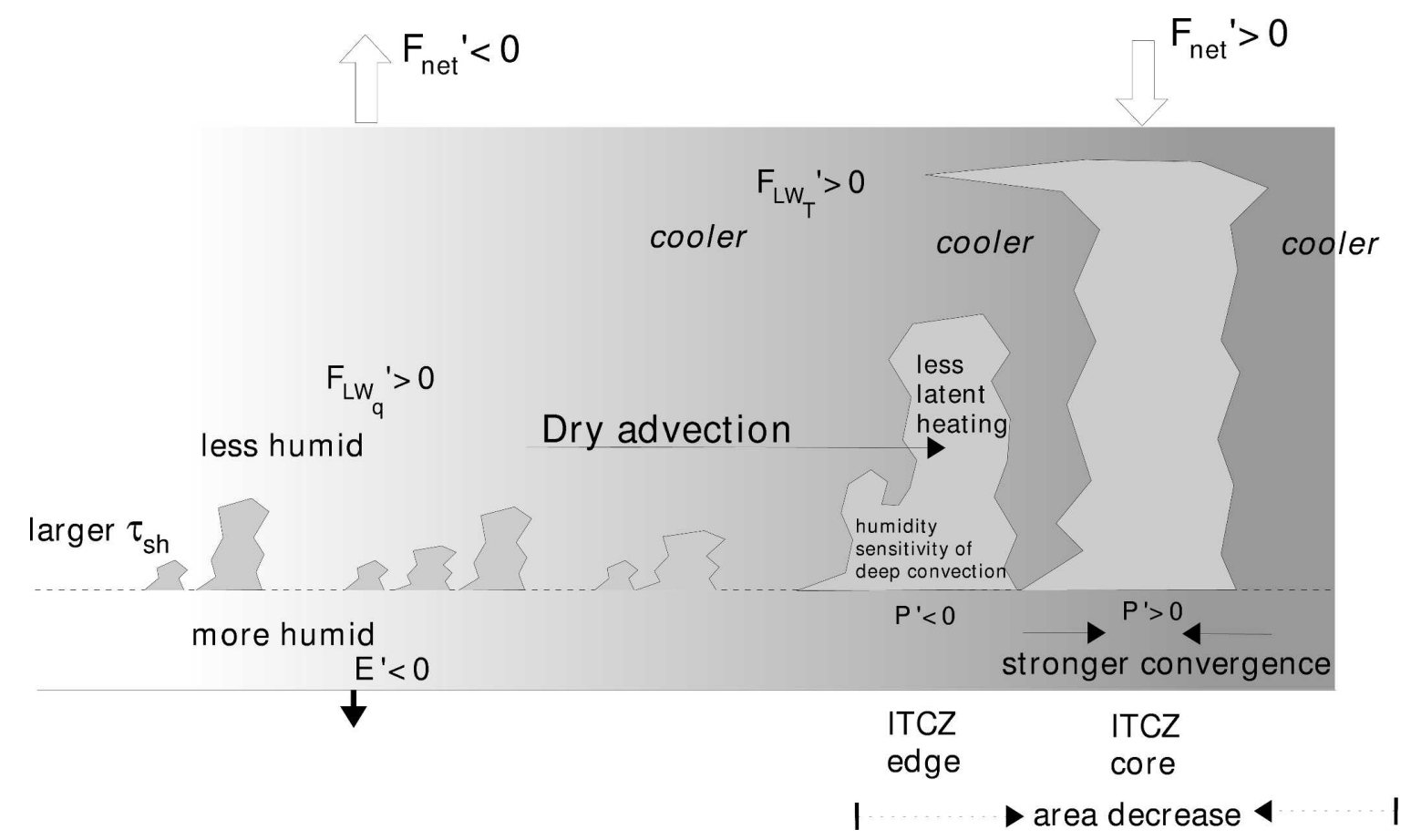

FIG. 18. Schematic summary of the interaction mechanisms between subtropical shallow cumulus and ITCZ deep convection, the $\mathrm{Cu}-q$ throttle. Only the major players in the interaction process are shown. The changes shown correspond to the scenario of weaker shallow cumulus (a larger shallow adjustment time scale $\tau_{\mathrm{sh}}$ ). The background shading represents the magnitude of the temperature change. The vertical arrows represent changes in energy fluxes into the atmospheric column (pointing away from the column indicates a decrease).

associated climatological change in tropical precipitation is on the order of several millimeters per day. The tropical temperature changes associated with the latent heating by precipitation are on the order of $1-2 \mathrm{~K}$. Furthermore, the water vapor path in the subtropics is affected by as much as $10 \mathrm{~mm}$ locally. These numbers suggest that vertical mixing by shallow cumulus needs to be accurately represented in GCMs. A corollary to this result is that a reduction in mixing by shallow cumulus in a warmer climate, for instance as a result of the stabilization of the lower troposphere through lapse rate effects, may lead to similar large-scale feedbacks.

The next logical question is what these results imply for GCMs in parts of this feedback mechanism that are not well represented. For example, Derbyshire et al. (2004) showed that many present-day GCM convection schemes still do not fully capture the sensitivity of deep convection to tropospheric humidity, possibly due to deficiencies in the entrainment formulation. Underestimation of the sensitivity of deep convection to humidity not only affects local cloud properties, but the energetics of the tropical climate system as a whole.

Acknowledgments. This research was supported in part by National Science Foundation Grants DMS-
0139666, ATM-0082529, ATM-0645200, and ATM0336849, and National Oceanic and Atmospheric Administration Grant NA05OAR4311134. The members of the Focused Research Group on tropical atmospheric dynamics are thanked for discussions that helped stimulate this research. We thank A. Sobel for the helpful feedback on an earlier draft of this paper, and D. Raymond for constructive comments.

\section{APPENDIX}

\section{Technical 2BF Implementation}

The introduction of a second degree of freedom for humidity in the QTCM implies an additional prognostic equation for humidity, one for the free troposphere and one for the atmospheric mixed layer $(k \in\{1,2\}$, respectively). Following the standard notation of the QTCM formulation by NZ00 these are written as

$$
\begin{aligned}
& \hat{b}_{1}\left(\partial_{t}+D_{q 1}\right) q_{1}-M_{1 q 1} \boldsymbol{\nabla} \cdot \mathbf{v}_{1}=\left\langle Q_{q}\right\rangle_{1}, \\
& \hat{b}_{2}\left(\partial_{t}+D_{q 2}\right) q_{2}-M_{1 q 2} \boldsymbol{\nabla} \cdot \mathbf{v}_{1}=\left\langle Q_{q}\right\rangle_{2}+\frac{g}{P_{2}} E_{s} .
\end{aligned}
$$


The terms $M_{1 q k}$ represent the gross moisture stratification for vertical motions induced by large-scale convergence of the baroclinic wind $\mathbf{v}_{1}$ in layer $k$ (note that the subscript 1 in $M_{1 q k}$ and $v_{1}$ refers to the basis functions for wind, which differ from those for humidity). The two prognostic humidity equations are coupled by the convective humidity tendency $\left\langle Q_{q}\right\rangle_{k}$. Here $E_{s}$ is the surface evaporation into the relatively shallow mixed layer. Further vertical redistribution into the free troposphere depends on the convective intensity $\left\langle Q_{q}\right\rangle_{k}$, described in section 3 .

The stratification terms $M_{1 q k}$ are calculated over the depth of each layer, as a function of the internal vertical structure functions of humidity $b_{k}(p)$ [see (6) and Fig. 1] and of baroclinic vertical velocity $\Omega_{1}(p)$, defined by NZ00 as

$$
\omega(p) \equiv \Omega_{1}(p) \nabla \cdot \mathbf{v}_{1} .
$$

This gives

$$
\begin{aligned}
M_{1 q k} & =\left\langle\Omega_{1} \partial_{p} q_{r}\right\rangle_{k}+\sum_{j=1}^{2}\left\langle\Omega_{1} \partial_{p} b_{j}\right\rangle_{k} q_{j}, \\
& \equiv M_{1 q_{r} k}+M_{1 q_{p} k},
\end{aligned}
$$

where $q_{r}$ is the reference humidity profile, a function only of pressure. In each layer both BFs contribute to the last term on the right-hand side, due to their small overlap at $p_{m}$. This overlap can be used for the formulation of either centered or upwind schemes for vertical advection. Suppose the overlap layer spans the pressure depth $\left\langle p_{m}-\varepsilon_{1}, p_{m}+\varepsilon_{2}\right\rangle$, where $\varepsilon_{1}+\varepsilon_{2}=\varepsilon$. The last term of (A5) then consists of a bulk integral and an integral over a part of the overlap layer,

$$
M_{1 q_{p} k} \equiv M_{1 q_{p} k}^{\text {bulk }}+M_{1 q_{p} k}^{\mathrm{int}} .
$$

Working out the interface term, using linear gradients of the structure functions $b_{k}(p)$ in the overlap layer, gives

$$
M_{1 q_{p} k}^{\mathrm{int}}=\frac{\Omega_{1}\left(p_{m}\right)}{P_{k}}\left(b_{2}^{-} q_{2}-b_{1}^{+} q_{1}\right) \frac{\varepsilon_{k}}{\varepsilon},
$$

where the superscripts + and - refer to the values of the structure function immediately above and below the overlap layer. Furthermore, $\varepsilon$ is assumed to be sufficiently small so that $\Omega_{1}(p)$ can be assumed constant in the overlap layer. For a centered advection scheme, set $\varepsilon_{1}=\varepsilon_{2}=1 / 2 \varepsilon$. For an upwind scheme, the last step is to make $p_{m}$ dependent on the model state. In subsidence conditions, $p_{m}$ is chosen such that $\varepsilon_{2}=\varepsilon, \varepsilon_{1}=0$, in effect including the overlap layer in layer 2 . In convergence conditions, $\varepsilon_{1}=\varepsilon, \varepsilon_{2}=0$. As a result, downward advection by large-scale subsidence dries the mixed layer when a humidity jump exists at the mixed-layer top. This corresponds to top entrainment of air into the convective mixed layer.

\section{REFERENCES}

Betts, A. K., 1975: Parametric interpretation of trade-wind cumulus budget studies. J. Atmos. Sci., 32, 1934-1945.

, 1986: A new convective adjustment scheme. Part I: Observational and theoretical basis. Quart. J. Roy. Meteor. Soc., 112, 677-691.

___, and M. J. Miller, 1986: A new convective adjustment scheme. Part II: Single column tests using GATE wave, BOMEX, ATEX and arctic air-mass data sets. Quart. J. Roy. Meteor. Soc., 112, 693-709.

Bretherton, C. S., M. E. Peters, and L. E. Back, 2004: Relationships between water vapor path and precipitation over the tropical oceans. J. Climate, 17, 1517-1528.

Chou, C., and J. D. Neelin, 2004: Mechanisms of global warming impacts on regional tropical precipitation. J. Climate, 17, 2688-2701.

,-- J.-Y. Tu, and C.-T. Chen, 2006: Regional tropical precipitation change mechanisms in ECHAM4/OPYC3 under global warming. J. Climate, 19, 4207-4223.

Derbyshire, S. H., I. Beau, P. Bechtold, J.-Y. Grandpeix, J.-M. Piriou, J.-L. Redelsperger, and P. M. M. Soares, 2004: Sensitivity of moist convection to environmental humidity. Quart. J. Roy. Meteor. Soc., 130, 3055-3079.

Gregory, D., 1997: Sensitivity of general circulation model performance to convective parameterization. The Physics and Parameterization of Moist Atmospheric Convection, R. K. Smith, Ed., NATO ASI Series C, Vol. 505, Kluwer Academic, 463-482.

Hansen, J., I. Fung, A. Lacis, D. Rind, S. Lenedeff, R. Ruedy, G. Russell, and P. Stone, 1988: Global climate changes as forecast by the Goddard Institute for Space Studies threedimensional model. J. Geophys. Res., 93D, 9341-9364.

Jakob, C., and A. P. Siebesma, 2003: A new subcloud model for mass-flux convection schemes: Influence on triggering, updraft properties, and model climate. Mon. Wea. Rev., 131, 2765-2778.

Johnson, R. H., T. M. Rickenbach, S. A. Rutledge, P. E. Ciesielske, and W. H. Schubert, 1999: Trimodal characteristics of tropical convection. J. Climate, 12, 2397-2418.

Lin, J. W.-B., J. D. Neelin, and N. Zeng, 2000: Maintenance of tropical intraseasonal variability: Impact of evaporation-wind feedback and midlatitude storms. J. Atmos. Sci., 57, 2793 2823.

Liu, W. T., W. Tang, and P. P. Niiler, 1991: Humidity profiles over the ocean. J. Climate, 4, 1023-1034.

McCaa, J. R., and C. S. Bretherton, 2004: A new parameterization for shallow cumulus convection and its application to marine subtropical cloud-topped boundary layers. Part II: Regional simulation of marine boundary layer clouds. Mon. Wea. Rev., 132, 883-896.

Neelin, J. D., and I. M. Held, 1987: Modeling tropical convergence based on the moist static energy budget. Mon. Wea. Rev., 115, $3-12$.

_ , and N. Zeng, 2000: A quasi-equilibrium tropical circulation model-Formulation. J. Atmos. Sci., 57, 1741-1766.

- and H. Su, 2005: Moist teleconnection mechanisms for the tropical South American and Atlantic sector. J. Climate, 18, 3928-3950. 
- C. Chou, and H. Su, 2003: Tropical drought regions in global warming and El Niño teleconnections. Geophys. Res. Lett., 30, 2275, doi:10.1029/2003GL018625.

Newell, R. E., and Y. Zhu, 1994: Tropospheric rivers: A one-year record and a possible application to ice core data. Geophys. Res. Lett., 21, 113-116.

_ N. E. Newell, and C. Scott, 1992: Tropospheric rivers?-A pilot study. Geophys. Res. Lett., 19, 2401-2404.

Ooyama, K., 1971: A theory on parameterization of cumulus convection. J. Meteor. Soc. Japan, 49, 744-756.

Parsons, D. B., K. Yoneyama, and J.-L. Redelsperger, 2000: The evolution of the tropical western Pacific ocean-atmosphere system following the arrival of a dry intrusion. Quart. J. Roy. Meteor. Soc., 126, 517-548.

Peters, O., and J. D. Neelin, 2006: Critical phenomena in atmospheric precipitation. Nature Phys., 2, 393-396.

Pierrehumbert, R. T., and H. Yang, 1993: Global chaotic mixing on isentropic surfaces. J. Atmos. Sci., 50, 2462-2480.

Riehl, H., C. Yeh, J. S. Malkus, and N. E. LaSeur, 1951: The northeast trade of the Pacific Ocean. Quart. J. Roy. Meteor. Soc., 77, 598-626.

Siebesma, A. P., and J. W. M. Cuijpers, 1995: Evaluation of parametric assumptions for shallow cumulus convection. J. Atmos. Sci., 52, 650-666.

Slingo, J. M., M. Blackburn, A. Betts, R. Brugge, B. J. Hoskins, M. J. Miller, L. Steenman-Clark, and J. Thurburn, 1994: Mean climate and transience in the tropics of the UGAMP GCM: Sensitivity to convective parameterization. Quart. J. Roy. Meteor. Soc., 120, 881-922.
Sobel, A. H., and C. S. Bretherton, 2000: Modeling tropical precipitation in a single column. J. Climate, 13, 4378-4392.

$\mathrm{Su}$, H., and J. D. Neelin, 2002: Teleconnection mechanisms for tropical Pacific descent anomalies during El Niño. J. Atmos. Sci., 59, 2682-2700.

- , and -2003 : The scatter in tropical average precipitation anomalies. J. Climate, 16, 3966-3977.

,-- , and C. Chou, 2001: Tropical teleconnection and local response to SST anomalies during the 1997-1998 El Niño. $J$. Geophys. Res., 106, 20 025-20 043.

$\longrightarrow,-$, and J. E. Meyerson, 2003: Sensitivity of tropical tropospheric temperature to sea surface temperature forcing. $J$. Climate, 16, 1283-1301.

Tiedtke, M., W. A. Heckley, and J. Slingo, 1988: Tropical forecasting at ECMWF: The influence of physical parameterizations on the mean structure of forecasts and analyses. Quart. J. Roy. Meteor. Soc., 114, 639-665.

Wang, Y., H. Xu, and S.-P. Xie, 2004: Regional model simulations of boundary layer clouds over the Southeast Pacific off South America. Part II: Sensitivity experiments. Mon. Wea. Rev., 132, 2650-2668.

Yanai, M., S. Esbensen, and J.-H. Chu, 1973: Determination of bulk properties of tropical cloud clusters from large-scale heat and moisture budgets. J. Atmos. Sci., 30, 611-627.

Zeng, N., J. D. Neelin, and C. Chou, 2000: A quasi-equilibrium tropical circulation model-Implementation and simulation. J. Atmos. Sci., 57, 1767-1796. 